\title{
Organized Turbulence in a Cold-Air Outbreak: Evaluating a Large-Eddy Simulation with Respect to Airborne Measurements
}

\author{
Pierre-Etienne Brilouet ${ }^{1,2}$ - Pierre Durand ${ }^{1} \cdot$ Guylaine Canut $^{2} \cdot$ Nadia Fourrié $^{2}$ \\ 1 Laboratoire d'Aérologie, CNRS, UPS, Université de Toulouse, Toulouse, France \\ 2 CNRM UMR 3589, CNRS, Université de Toulouse, Météo-France, Toulouse, France
}

\begin{abstract}
Cold-air outbreaks (CAO) lead to intense air-sea interactions, the appropriate representation of which are fundamental for climate modelling and numerical weather forecasting. We analyze a CAO event with low-level wind speeds of approximately $25 \mathrm{~m} \mathrm{~s}^{-1}$ observed in the north-western Mediterranean Sea. The marine atmospheric boundary layer (MABL) was sampled with an aircraft equipped for turbulence measurements, revealing the organization of the MABL flow in coherent structures oriented along the mean wind direction, which was then simulated in two steps. First, a one-dimensional simulation enabled the determination of the forcing terms (particularly horizontal advection) required to adequately reproduce the vertical structure of the MABL flow. These terms were computed from a limited-area forecast model in operation during the entire field campaign. Then, a large-eddy simulation (LES) was performed during the well-established phase of the CAO event. The LES output is validated with respect to airborne data, not only with respect to the mean wind-speed and thermodynamic profiles, but also the turbulence statistics and coherent structures. The validated LES results enable description of the turbulent field as well as the coherent structures. The main discrepancy is a considerable underestimation of the simulated evaporation (computed with a parametrization of the turbulent surface fluxes), and hence of the moisture fluctuations throughout the boundary layer. Several possible explanations may explain this underestimation. The structure of the boundary layer is nonetheless well reproduced by the LES model, including the organized structures and their characteristic scales, such as the structure wavelength, orientation, and aspect ratio, which closely agree with observations. A conditional-sampling analysis enables determination of the contribution of the coherent structures to the vertical exchange. Although they occupy a limited fractional area, organized structures are the primary contributors to the turbulent exchange.
\end{abstract}

Keywords Cold-air outbreak · Large-eddy simulation · Marine atmospheric boundary layer - Turbulence organization

Pierre-Etienne Brilouet

pierre-etienne.brilouet@aero.obs-mip.fr 


\section{Introduction}

As oceans cover more than $70 \%$ of the Earth's surface, the study of mass and energy transfer between the ocean and the atmosphere is fundamental not only for climate issues but also to short- and medium-term weather forecasting. By definition, the marine atmospheric boundary layer (marine $\mathrm{ABL}, \mathrm{MABL}$ ) interacts directly with the surface and is the seat of complex processes acting on a large range of temporal and spatial scales. Inside the MABL, mass and energy exchanges between the surface and the free atmosphere are made through turbulence processes. In practice, the surface turbulent fluxes are computed with bulk parametrizations (Liu et al. 1979) based on the Monin-Obukhov similarity theory (MOST). The complexity of many of these parametrizations is highly variable depending on the parameters taken into account, such as waves, sea spray, or gusts. Among the existing bulk formulations, the Coupled Ocean-Atmosphere Response Experiment (COARE) algorithm (Fairall et al. 2003) is efficient on a large range of flow regimes (wind speeds up to $20 \mathrm{~m} \mathrm{~s}^{-1}$ ) and it is widely used by oceanic and atmospheric modellers (Weller et al. 2004; Lebeaupin Brossier et al. 2008). We also note the parametrization developed by Moon et al. (2007) for hurricane conditions, and the work of Andreas et al. (2015), who introduced a new approach to take into account sea spray. These flux formulations agree quite well under moderate wind speeds, but uncertainties become important at low or high wind speeds or under strong stratification (Brunke et al. 2003).

The dynamics of the ABL have been described in numerous experimental studies, but mainly over continental surfaces. Access difficulties have meant that the number of field campaigns carried out over the sea is much lower than over land, but the development of autonomous platforms and instrumented aircraft has led to many advances. Understanding air-sea exchange mechanisms such as the redistribution of the energy from the surface to the atmosphere in terms of sensible and latent heat fluxes is especially challenging and crucial in high wind speeds for adapting the current turbulent surface-flux parametrizations and correctly representing the evolution of the MABL structure. This is particularly significant during cold-air outbreaks (CAO), when cold and dry continental airmasses are advected over a warmer open water area during high wind speeds. During these events, energy exchange between the open sea surface and the atmosphere can be immense: during the GALE campaign (Genesis of Atlantic Lows Experiment), Grossman and Betts (1990) observed a total (sensible + latent) heat flux of $1174 \mathrm{~W} \mathrm{~m}^{-2}$, a maximum value of $880 \mathrm{~W} \mathrm{~m}^{-2}$ was observed during the MASEX campaign (Mesoscale Air-Sea Exchange) (Chou 1993) and, more recently, a total flux of $917 \mathrm{~W} \mathrm{~m}^{-2}$ was deduced from airborne measurements (Brilouet et al. 2017) during the HyMeX-SOP2 field campaign (HYdrological cycle in the Mediterranean EXperiment, special-observation period 2).

In response to large air-sea exchange during CAO events, the MABL flow often consists of coherent structures, which tend to occur more frequently over homogeneous surfaces, such as the open ocean, whereas surface heterogeneities over continental areas are a limiting factor. Coherent structures were observed during a number of field campaigns, such as the KONTUR campaign (CONvection and TURbulence) (Brümmer et al. 1985) off Greenland, the GALE campaign off the U.S.A. coast, and the BOMEX campaign (Barbados Oceanographic and Meteorological Experiment) (Grossman 1982). The climatological study of Brümmer and Pohlmann (2000) notes the occurrence of organized convective structures over the seas around Greenland and the Barents Sea region more than $50 \%$ of the time during winter. These features have been widely examined using satellite observations, since cloud streets can be observed under sufficiently moist conditions (Brown 1980; Renfrew and Moore 1999). Clouds act 
as tracers, allowing the identification of a particular organization, but this organization can also occur in clear-sky conditions (Weckwerth et al. 1996). As mentioned by Atkinson and Zhang (1996), organized structures can develop into very different shapes for which Young et al. (2002) proposed three main classes: convective rolls, open cells, and closed cells. The convective rolls are mainly oriented along the mean wind direction, with a characteristic wavelength (i.e. the width of a pair of counter-rotating rolls) ranging between 2 and $20 \mathrm{~km}$, whereas the downwind longitudinal extension of these rolls into helical eddies (Tsinober and Levich 1983; Etling and Brown 1993) can reach between 10 and $100 \mathrm{~km}$. With a roll wavelength corresponding to several times the depth of the MABL (hereafter denoted as $z_{i}$ ), convective rolls occupy the spectral domain contributing most to the turbulence kinetic energy (TKE, $e$ ) (LeMone 1976). Organized structures play a major role in the vertical transport of mass and energy (Chou and Ferguson 1991), but this contribution is not fully understood and is still an issue for turbulence parametrizations in weather forecast and climate models.

Most previous studies on CAO events and organized convective structures were based on observations collected during large field experiments or from satellites. Despite limitations in computer resources, some numerical studies were conducted (Etling and Raasch 1987) to investigate the development of roll vortices with a two-dimensional model, but current advances in computing power has enabled numerical modelling of higher resolution. Largeeddy simulation (LES) refers to a simulation with a grid fine enough to explicitly resolve the eddies containing most of the TKE and responsible for most of the turbulent transfers (Pope 2000). Chlond (1992) and Müller and Chlond (1996) used a three-dimensional model to explicitly represent the large-scale motions of an observed cloud street with cell broadening. The LES approach has become a frequent tool for process studies, such as in Zurn-Birkhimer et al. (2005) who focused on the effects of buoyancy and shear on convective structures over Lake Michigan, or Salesky et al. (2017) who investigated the transition between rolls and convective cell structures, and their impact on the turbulent transport efficiency. The LES approach can also be used for the improvement of parametrizations in coarser resolution models, such as in Pergaud et al. (2009) who improved a turbulence scheme by including a non-local turbulent transport term, thus combining the classical local-turbulence and massflux concepts. Even though CAO events represent interesting opportunities for improving the understanding of vertical mixing processes in MABL flows (Morrison et al. 2012; Tomassini et al. 2017), LES studies of such events are scarce. Liu et al. (2004) and Gryschka and Raasch (2005) performed simulations reproducing roll clouds generated by the convective instability during CAO events. By varying the upstream characteristics, the LES approach of Gryschka et al. (2014) produced roll and non-roll cases to characterize a roll's contribution to the vertical turbulent transport. Salesky et al. (2017) realized a set of simulations with different stability conditions, from neutral to highly convective. An intercomparison of several LES studies performed on a CAO case was made by de Roode et al. (2019) to improve the current parametrization schemes used in weather prediction models.

Studies combining the LES approach and in situ measurements of turbulence during CAO events are even less numerous. Müller et al. (1999) used a numerical model to simulate the convective pattern observed with aircraft measurements and synthetic-aperture-radar satellite images. The MABL turbulence structure in high wind speeds has recently been studied using airborne measurements performed during the HyMeX-SOP2 field campaign in Brilouet et al. (2017) with a statistical approach based on the whole multi-day dataset. Here, we focus on a specific episode to complete the analysis of these observations. The LES model provides us with three-dimensional fields evolving in time, giving access to MABL characteristics that cannot be obtained from observations alone. The aircraft observations enable an evaluation of whether the LES approach produces a realistic MABL structure, after 
(a)

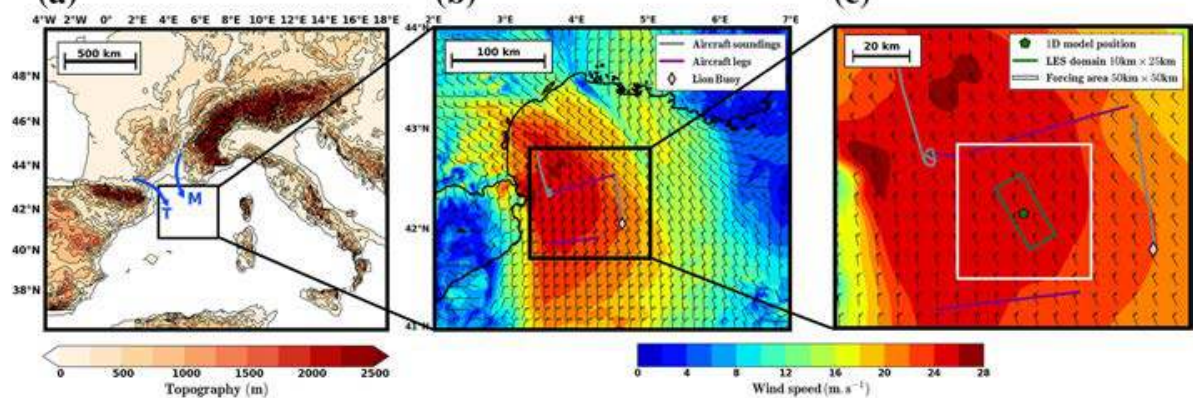

Fig. 1 a Map of the north-western Mediterranean. Blue arrows represent the local flow $(\mathrm{M}=\mathrm{Mistral}$ and $\mathrm{T}=$ Tramontane). b Magnification of the Gulf of Lion where the HyMeX-SOP2 field campaign occurred in winter 2013 with the ground tracks of aircraft flights on 13 March 2013: profiles in grey, and stacked straight and level runs in purple. The pink diamond marks the position of the Lion buoy. c Magnification of the modelling areas: the green pentagon marks the position of the one-dimensional simulation, the LES domain is indicated by the green rectangle, and the white square represents the area over which the forcing terms are calculated. The velocity vectors in (b) and (c), as well as the wind speed (colour scale), are forecasted by the AROME-WMED model for 13 March 2013 at 1500 UTC

which turbulent processes from the LES output may be analyzed in more detail, particularly the impact of turbulence organization on the vertical exchange. Below, the chosen case study and the adopted strategy are described in Sect. 2, while Sect. 3 is devoted to the onedimensional simulations performed to establish the set-up of the LES model. The validation of the LES results against airborne measurements is presented in Sect. 4, Sect. 5 is dedicated to the analysis of turbulence organization and vertical energy exchanges, and the last section contains a discussion of the main results.

\section{Case Study and Modelling Strategy}

\subsection{Observations}

\subsubsection{Overview of the HyMeX-SOP2 Field Campaign}

The north-western Mediterranean is favourable for the generation of high wind speeds by orographic channeling of the synoptic flow, as schematically represented in Fig. 1a. Flamant and Pelon (1996) detailed the formation mechanisms and the meteorological conditions leading to Tramontane and Mistral flows. In winter, Tramontane and Mistral flows result in CAO events transporting cold and dry continental air over the warmer sea, when significant air-sea heat exchange occasionally reaches $1000 \mathrm{~W} \mathrm{~m}^{-2}$ (Mertens and Schott 1998; Flamant 2003). The recurrence of CAO events in the Gulf of Lion (Fig. 1b) cools the surface and introduces water vapour inside the MABL flow, resulting in an oceanic mixed layer becoming cooler and saltier than the deeper water layers, which, because of the dense-water formation, can trigger oceanic convection or vertical mixing throughout the water column.

In this context, the second special observation period (SOP2) of the HyMeX field campaign was conducted over the north-western Mediterranean Sea during the winter of 2013 to identify and understand the processes involved during high wind speeds and strong oceanic convection. Estournel et al. (2016) provide a global view of the observational strategy and a 
description of the instrumentation deployed to monitor both oceanic and atmospheric parameters. Two platforms are considered here: (1) a moored buoy operated by Météo-France (hereafter the Lion buoy) located where oceanic convection was expected (Fig. 1a), and equipped to measure atmospheric parameters, sea surface temperature (SST) and salinity. Estournel et al. (2016) and Brilouet et al. (2017) report the meteorological conditions encountered during winter 2013, including several CAO events associated with high wind speeds. (2) The French ATR42 aircraft, which performed 11 flights during intense observation periods (IOP), allowing us to investigate the MABL structure. The mean characteristics of the MABL flow (i.e. profiles of potential temperature, specific humidity, and velocity) were monitored with a vertical sounding at the beginning — and sometimes at the end —of an airborne sampling period. The turbulence field was investigated through stacked, straight and level legs at different heights inside the MABL. More details about the flight strategy and data processing (in particular, estimates of turbulence parameters) can be found in Brilouet et al. (2017), who analyzed the turbulence structure and its non-isotropic character because of the frequent organization of the MABL flow into coherent structures aligned with the mean wind direction.

\subsubsection{Presentation of the Case Study}

The choice of IOP was motivated by the quality of available observations to validate the simulation and the representativeness of intense air-sea exchange. The 13 March 2013 (IOP28) was selected from 11 flights operated during the HyMeX-SOP2 field campaign. Figure 2 presents the atmospheric conditions before and during the CAO event, with wind speeds $<5 \mathrm{~m} \mathrm{~s}^{-1}$ for several days and moderate wind speeds observed on 12 March 2013. During the night between 12 and 13 March 2013, the wind speed was low, but then progressively increased during the morning until establishing a Tramontane event in the afternoon, during which the wind speed observed at the Lion buoy reached 22-23 $\mathrm{m} \mathrm{s}^{-1}$. The SST was characterized by a weak diurnal cycle during the period 9-11 March, followed by a continuous decrease throughout the period $12-13$ March. However, this decrease was $<0.2{ }^{\circ} \mathrm{C}$, whereas the temperature difference between the sea surface and the air (close to zero before the CAO event) drastically increased, reaching $7^{\circ} \mathrm{C}$ in the afternoon. The various terms of the surface energy budget, presented in Fig. 2, can be expressed as

$$
G=H+L E+S_{\text {net }}+L_{\text {net }},
$$

where $H$ is the sensible heat flux, $L E$ the latent heat flux (with $E$ the evaporation and $L$ is the latent heat of vaporization), $S_{\text {net }}$ and $L_{\text {net }}$ the net shortwave and longwave radiation fluxes, respectively, and $G$ is the resulting heat gain for the sea. The terms on the right-hand side of the equation are positive when directed towards the surface. Between 9 and 11 March, this budget is dominated by the radiation terms, as the turbulent fluxes are one order of magnitude lower. On 12 March, there is considerable evaporation associated with the increase in wind speed, reaching $170 \mathrm{~W} \mathrm{~m}^{-2}$ in the afternoon. In the evening, the wind speed reduced, and the heat fluxes returned to very low values. On 13 March, the surface turbulent fluxes increased throughout the day, becoming much larger than the radiative fluxes in the afternoon, leading to a strong heat loss $G$ for the sea, a characteristic of the so-called heat pumping. This IOP is well documented, with two aircraft profiles and stacked runs of 70-90 km performed across the mean flow in two areas as depicted in Fig. 1b, c. The profiles, located in the north-western and eastern parts of the study area, were realized on straight and slanted runs, up to around a height of $2 \mathrm{~km}$. They were approximately $70 \mathrm{~km}$ and $60 \mathrm{~min}$ apart, and revealed significant 

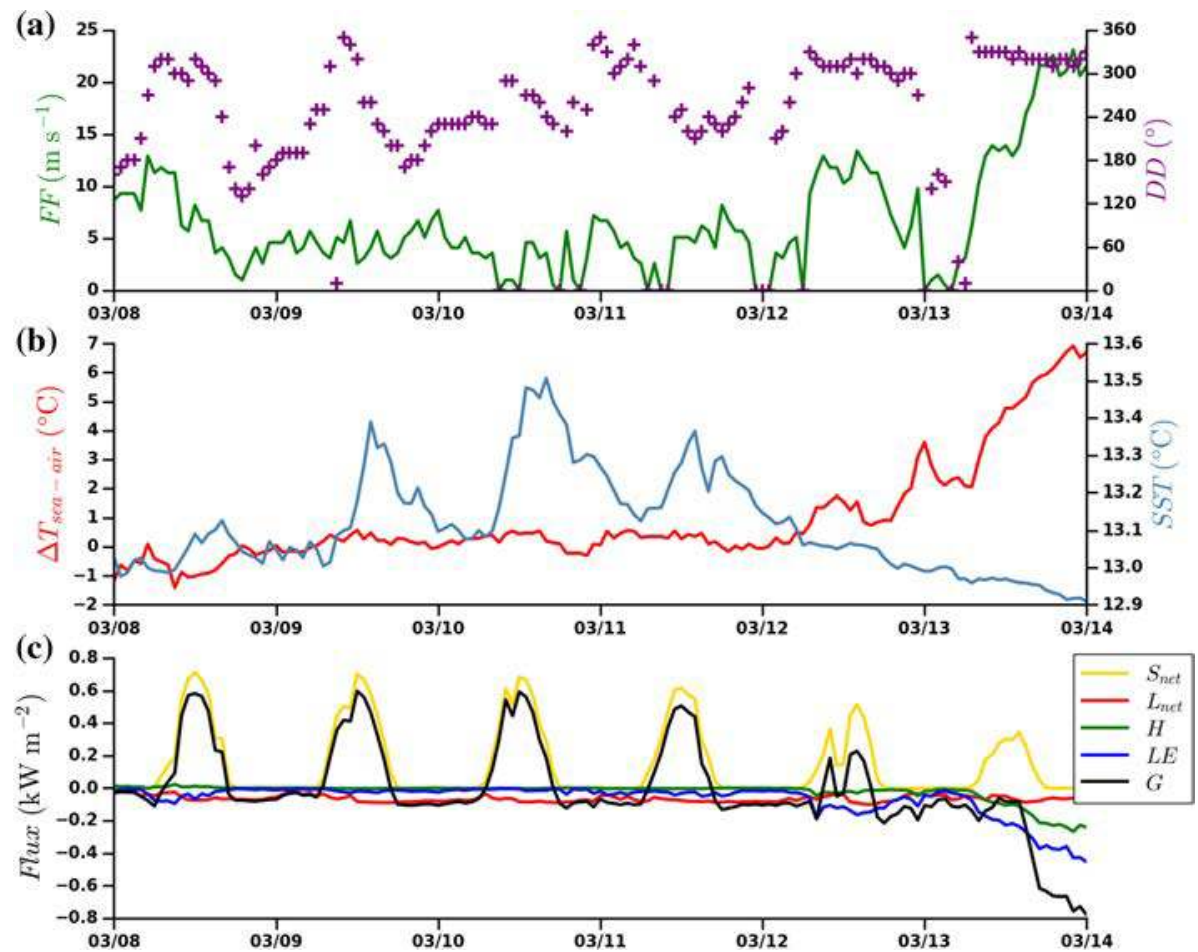

Fig. 2 Time series of the observations at the Lion buoy in the period 8-14 March 2013. a Wind speed (FF, green) and wind direction ( $D D$, purple crosses); b SST (blue) and the difference between the SST and the air temperature (red); c net radiative shortwave $\left(S_{\text {net }}\right.$, yellow) and longwave ( $L_{\text {net }}$, red) fluxes, sensible heat flux ( $H$, green), latent heat flux ( $L E$, blue), and net heat flux $(G$, black). All fluxes are counted positive when they correspond to a gain of energy for the sea

differences in the MABL characteristics, reaching $1 \mathrm{~g} \mathrm{~kg}^{-1}$ and $2.5^{\circ} \mathrm{C}$ for specific humidity and potential temperature, respectively. In contrast, the MABL thickness was of the order of 600-700 $\mathrm{m}$ and similar in the two areas. The observers on board the ATR42 flight reported a fractional cloud cover over the flight area, with organization into cloud bands. Unfortunately, as it was not possible to obtain more precise information from the aircraft instrumentation, we use a combination of satellite pictures and simulation output to attempt to describe the cloud cover as described in the Appendix.

The stacked straight and level legs were performed perpendicular to the mean wind direction at three altitudes $z\left(z / z_{i}=0.4,0.6\right.$, and 0.8$)$ to investigate the MABL turbulence structure. Figure 3 shows the vertical velocity component, potential temperature, and humidity fluctuations collected during a leg flown at the height $z / z_{i}=0.8$, where well-defined organized structures are seen in all three signals, albeit less obvious for the specific humidity. Nevertheless, the corresponding normalized spectra are quite similar and exhibit a peak at an identical wavenumber for all the parameters, corresponding to a wavelength of around $2400 \mathrm{~m}$. Such an organization has already been reported during CAO events, for example, by Renfrew and Moore (1999), who observed roll vortices with a characteristic wavelength of 4-5 km from aircraft data collected over the Labrador Sea, although the signature was more evident in the water vapour than in the temperature signal. The organization of the turbulence field into convective rolls, as observed here, was quantified in terms of spectral 

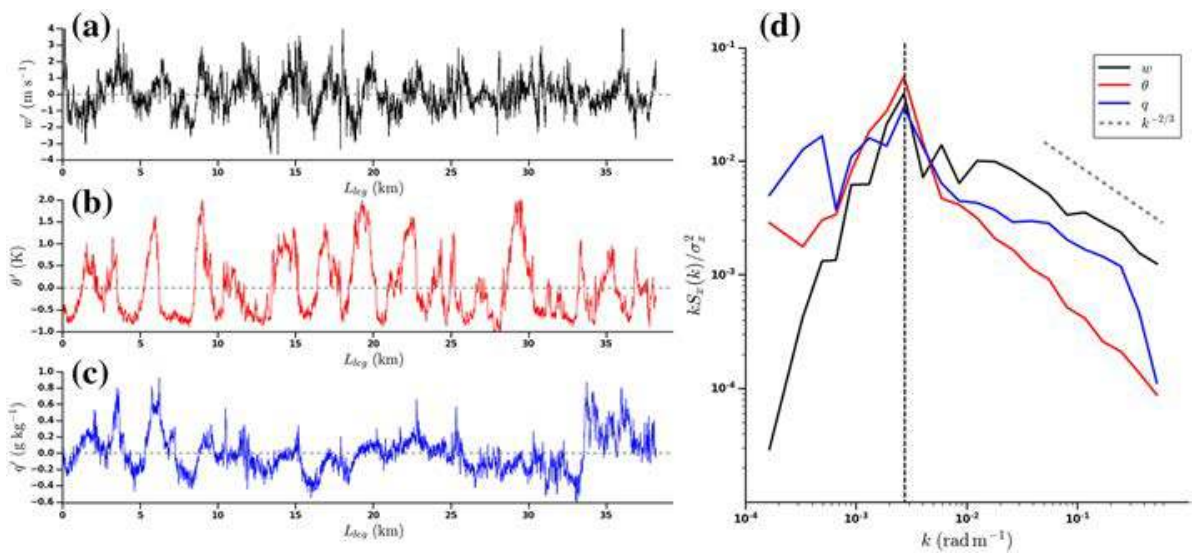

Fig. 3 Measured fluctuations of the a vertical velocity component $w^{\prime}, \mathbf{b}$ potential temperature $\theta^{\prime}$, and $\mathbf{c}$ specific humidity $q^{\prime}$ along a crosswind leg flown at the height $z / z_{i}=0.8$. d Corresponding normalized spectra. The vertical line indicates the spectral peak and the oblique dashed line represents the $-2 / 3$ slope of the inertial subrange

characteristics using a statistical treatment of the airborne measurements from the whole field campaign by Brilouet et al. (2017). Our objective here is to evaluate the capacity of the numerical simulations to correctly reproduce the MABL characteristics during a CAO event, and, in particular, the convective rolls associated with high wind speeds.

\subsection{Set-Up of the Numerical Simulations}

\subsubsection{Description of the Model}

All simulations were performed with the MESO-NH non-hydrostatic meteorological research model, which is able to represent the flow over a large range of resolutions, from the synoptic scale down to turbulent scales. An overview of the model and its applications is given by Lac et al. (2018). Due to the non-hydrostatic nature of the model, pressure fluctuations are computed, meaning that the vertical acceleration components are needed to correctly simulate the convection processes. The acoustic domain is filtered through an anelastic system of equations (Durran 1989). The prognostic variables are the three velocity components $(u, v, w)$, the potential temperature $\theta$, the mixing ratio of different types of hydrometeors, the TKE $e$, and possible reactive or passive scalars. A fourth-order centred-advection scheme is used for the momentum components associated with a fourth-order explicit Runge-Kutta method for the temporal discretization. The choice of the spatial and temporal schemes was conditioned by a stability constraint needed to ensure numerical convergence and to fulfil the Courant-Friedrichs-Lewy (CFL) condition. To achieve a sufficiently high horizontal resolution, the high wind speeds encountered in this case study imply a small timestep. As detailed in Lunet et al. (2017), a combination of the advection scheme and Runge-Kutta method results in a CFL condition that is not too restrictive. Furthermore, Ricard et al. (2013) have shown that this dynamical configuration is well adapted to the LES approach. The scalar variables are transported with the piecewise parabolic method (Colella and Woodward 1984).

Concerning the physical parametrizations, the microphysics is handled by the ICE3 scheme (Pinty and Jabouille 1998), which includes six hydrometeor species (water vapour, 
cloud droplets, raindrops, pristine ice crystals, snow or aggregates, and graupel). No radiative transfer scheme is used. The subgrid-turbulence scheme (Cuxart et al. 2000) is based on the approach of Redelsperger and Sommeria (1986), with a 1.5-order closure based on a prognostic TKE equation, and able to be used for a large range of resolutions with the same set of equations. The one-dimensional version is used when the horizontal resolution is coarse enough such that all the turbulent scales are smaller than the size of the mesh, and the turbulence terms are, therefore, completely parametrized; the three-dimensional version is deployed in the LES configuration. The mixing length used to compute the turbulent viscosity depends on the configuration. For one-dimensional simulations, the mixing length of Bougeault and Lacarrère (1989) is used, whereas for LES resolutions, the mixing length can be viewed as the largest subgrid eddies equalling the cubic root of the product of the three mesh sides (Deardorff 1980), with a correction depending on stratification.

\subsubsection{From the One-Dimensional Approach to the Large-Eddy Simulation}

As a first step, several tests were conducted with the model in a single-column version to develop a reference configuration suitable for the LES model. During this step, we conducted sensitivity studies with regard to the large-scale forcing and to the turbulent surface fluxes to reproduce a realistic MABL structure. As the LES domain is of limited area, the large-scale conditions must be prescribed, and these play a crucial role in the local MABL structure (Bellon and Stevens 2012; Vogel et al. 2016), especially during a CAO event when the horizontal advection of temperature and humidity is large. The estimation of the large-scale conditions is non-trivial, but is commonly performed using operational model analyses. Here, the largescale forcing (advection) is computed from the output of the limited-area numerical weather prediction model AROME-WMED (Application of Research to Operations at Mesoscale dedicated to the Western Mediterranean Sea). Once the reference set-up has been defined, the large-scale forcing and the surface fluxes validated for the one-dimensional model were identically applied to each vertical column of the LES domain, which implicitly assumes that these forcing terms do not vary horizontally inside the domain.

\subsubsection{Prescribing the Atmospheric Forcing}

The AROME-WMED model (Fourrié et al. 2015) is an adapted version of the French operational limited-area model AROME (Seity et al. 2011), which provided forecasts during the HyMeX field campaign, helping to initiate each IOP and the deployment of specific measurement platforms (such as the ATR42 aircraft) during favourable meteorological conditions. The AROME-WMED model is centred on the western Mediterranean area, and was run with a $2.5-\mathrm{km}$ horizontal resolution with 60 vertical levels stretched from $10 \mathrm{~m}$ above the surface up to $1 \mathrm{hPa}$. Each day at $0000 \mathrm{UTC}$, a 48-h forecast was initialized from the three-dimensional assimilation, taking into account observations in the temporal range (2230-0130 UTC), with forecasts available every hour. The surface fluxes of heat and momentum were computed using the Exchange Coefficients from Unified Multi-campaigns Estimates (ECUME) parametrization (Belamari 2005). After the campaign, as performed for the second AROME-WMED reanalysis of the SOP1 (Fourrie et al. 2019), the model was run again with the COARE 3.0 parametrization (Fairall et al. 2003), resulting in reduced values of the sensible heat flux for high wind speeds, in better agreement with the observations (Brilouet et al. 2017). This latter version is, therefore, used here.

The quality of the AROME-WMED simulation was assessed with respect to the aircraft observations on the afternoon of 13 March by comparing simulated and observed profiles of 
(a)

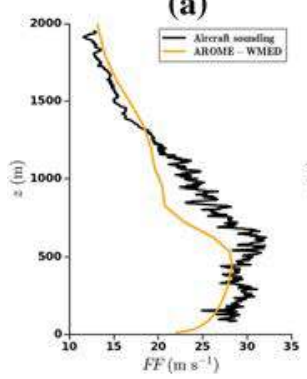

(b)

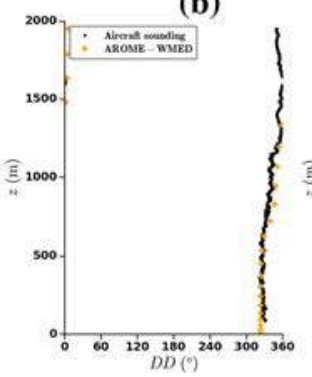

(c)

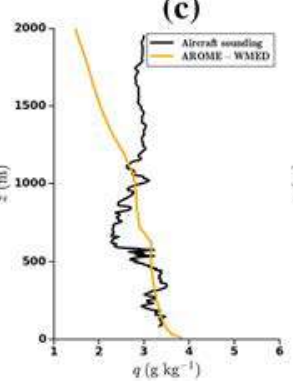

(d)

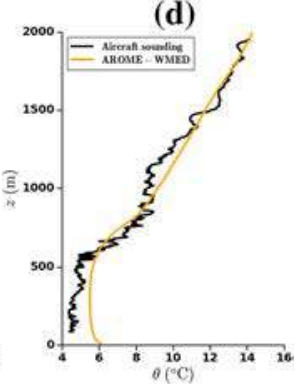

Fig. 4 Vertical profiles of a wind speed, $\mathbf{b}$ wind direction, $\mathbf{c}$ specific humidity and $\mathbf{d}$ potential temperature from the aircraft sounding (black) and the AROME-WMED forecast for 13 March at 1500 UTC at the nearest grid point to the aircraft track (orange)

wind speed, temperature and specific humidity as presented in Fig. 4. The simulated profiles are chosen as close as possible in time (less than $30 \mathrm{~min}$ ) and location to the observations. The agreement between the profile shapes for temperature (and therefore the MABL thickness), the wind speed and direction, and the moisture content in the MABL can be regarded as very good. The only failures in the model profiles are a temperature that is too high (by about $1{ }^{\circ} \mathrm{C}$ ) in the lower half of the MABL, a wind speed that is too low (by about $3 \mathrm{~m} \mathrm{~s}^{-1}$ ) in the upper half of the MABL and in the layer immediately above, and a free troposphere that is too dry. Below, such discrepancies are shown to be within the space and/or time variability observed during the flight. We can therefore rely on the AROME-WMED fields to compute the forcing terms for the MESO-NH simulations.

The AROME-WMED model output is used to compute the outer-scale terms that cannot be resolved by the one-dimensional and LES models, such as the geostrophic forcing and the advection of heat and moisture. As these forcing terms are of great importance in the episode analyzed here because the wind speed is high and the horizontal gradients of temperature and moisture are observed in relation to the progressive heating and moistening of the flow over the sea, the simulation of a realistic MABL by the one-dimensional and LES configurations requires an accurate estimation of these forcings. Furthermore, these terms have to be computed on a domain of a size relevant to the local simulations. After different tests, we chose to compute these terms over a horizontal domain of $50 \mathrm{~km} \times 50 \mathrm{~km}$, centred on the local simulation domain (the white square in Fig. 1c), as the variability (and therefore uncertainty) of the estimates is too large for smaller domains, and larger domains would involve information that is not relevant to the local simulations. In other words, the $50 \mathrm{~km} \times 50 \mathrm{~km}$ domain is the optimal one for providing a realistic variability (in time and along the vertical coordinate) of the estimates. In the simulations, the profile of the geostrophic wind speed as well as of the advection of heat and moisture is thus prescribed, but no horizontal variation of these terms is considered, implying they have the same value for all the horizontal meshes of the LES model.

The advection terms of heat and moisture are diagnosed as total advection terms combining the horizontal and the vertical contributions, which indirectly take into account the large-scale vertical velocity component through those tendencies. The time-height cross-sections of the potential-temperature and specific-humidity advection during the $\mathrm{CAO}$ event is presented in Fig. 5. In the lower part of the MABL for $z<500 \mathrm{~m}$, the Tramontane flow is associated with the transport of cold and dry air, resulting in cooling and drying rates reaching $-2.2 \mathrm{~K} \mathrm{~h}^{-1}$ and $-0.82 \mathrm{~g} \mathrm{~kg}^{-1} \mathrm{~h}^{-1}$, respectively. Such values in a 700-m-thick boundary layer would 

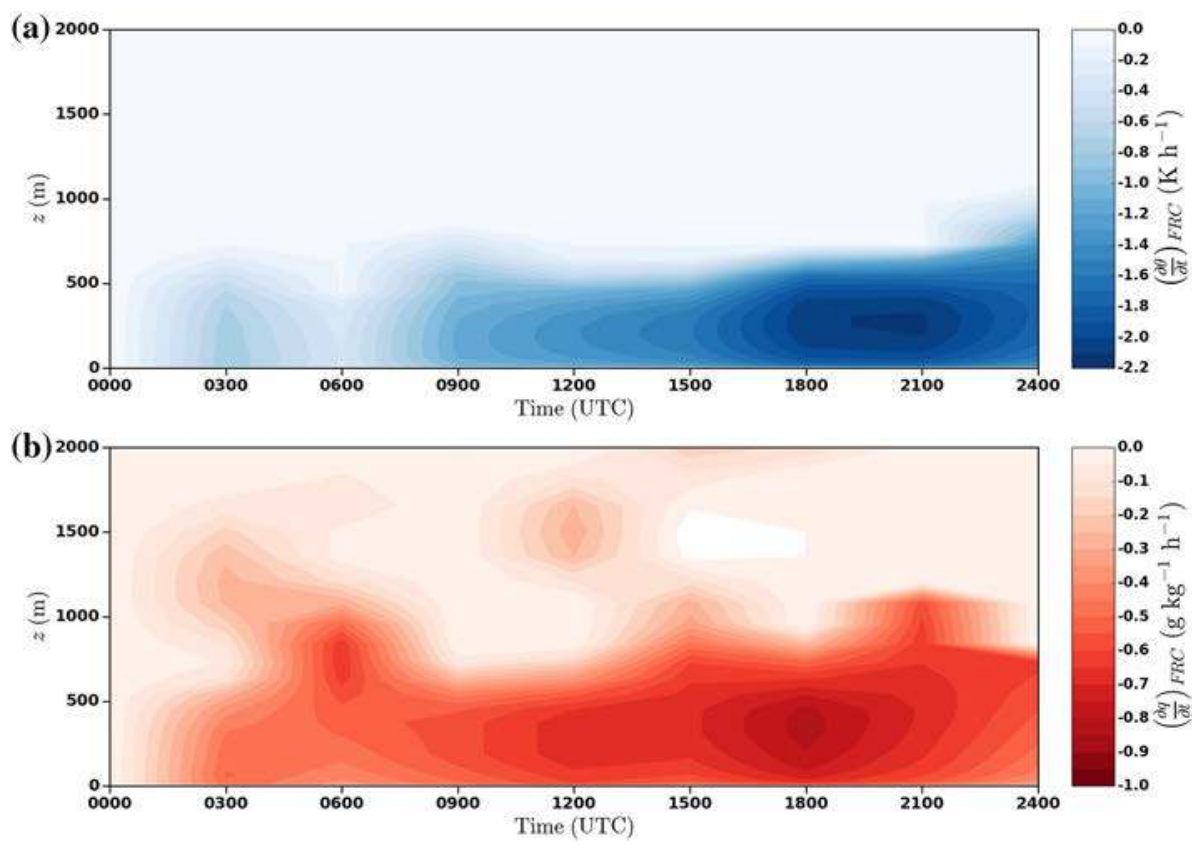

Fig. 5 Time-height cross-sections of potential-temperature (a) and specific-humidity (b) advection terms deduced from AROME-WMED model outputs for 13 March 2013

require surface sensible heat and latent heat fluxes of the order of $500 \mathrm{~W} \mathrm{~m}^{-2}$ to maintain the steady-state heat and moisture content of the MABL (in other words, a balance between advection and turbulent transfers). In the upper part of the MABL and the lower troposphere, the advection terms are much less important because the wind speed is lower and the contrast between the continental and marine air masses aloft is not as high as within the Tramontane flow.

While the large-scale advection of momentum cannot be prescribed in the version of the MESO-NH model used here, it appears from Fig. 1c that the wind speed does not vary much over the area of interest. With an order of magnitude for the wind-speed variation of $1 \mathrm{~m} \mathrm{~s}^{-1}$ over a distance of $50 \mathrm{~km}$, and a wind speed of $25 \mathrm{~m} \mathrm{~s}^{-1}$, the advection term in the momentum equation is of the order of $5 \times 10^{-4} \mathrm{~m} \mathrm{~s}^{-2}$. The order of magnitude of the friction term could be estimated as $u_{*}^{2} / z_{i}$, where $u_{*}$ is the friction velocity. With $u_{*}=1.1 \mathrm{~m} \mathrm{~s}^{-1}$ and $z_{i}=750 \mathrm{~m}$, as was observed during the situation analyzed here, a value of $1.6 \times 10^{-3} \mathrm{~m} \mathrm{~s}^{-2}$ for the friction term is obtained. The advection term thus remains much smaller than the friction term, but it cannot be considered as negligible, so that the simulated wind speed could be slightly biased, and has to be taken into account in the analysis of the results.

The geostrophic velocity $\mathbf{U}_{\mathbf{g}}$ resulting from the equilibrium of Coriolis and pressure forces cannot be directly diagnosed from the AROME-WMED model output because the parameters needed for its computation were not available. The profile of geostrophic wind speed $\left(F F_{g}\right)$ was thus constructed as follows: above $1000 \mathrm{~m}$, the effect of surface friction vanishes and the term $F F_{g}$ equals the actual wind speed. Below $500 \mathrm{~m}$ (approximately representing the height of the Tramontane flow), the value of $F F_{g}$ is constant and proportional to the actual wind speed at $500 \mathrm{~m}\left(F F_{g}=\alpha F F_{500}\right.$, with $\left.\alpha=5 / 4\right)$. Between 500 and $1000 \mathrm{~m}, F F_{g}=\beta(z) F F(z)$, with $\beta(z)=\alpha-(\alpha-1)(z-500) /(1000-500)$. In the first tests, the wind direction inside 
the MABL appeared to deviate by about $30^{\circ}$ from the geostrophic wind direction. In order for the simulated MABL wind direction to be aligned with the long side of the domain, the geostrophic wind direction is thus prescribed as $D D_{g}=350^{\circ}$, leading to a MABL wind direction $D D=320^{\circ}$.

The geostrophic velocity and advection terms are computed every $3 \mathrm{~h}$ from the AROMEWMED model output, and then linearly interpolated to each timestep of the local simulations.

\section{One-Dimensional Simulations}

The objective of the one-dimensional simulations is to evaluate the mean MABL development during the CAO event and to establish the reference set-up for the LES model. The simulations, initialized with the profiles at 0000 UTC from the AROME-WMED model at the corresponding location (green mark in Fig. 1c), lasted $24 \mathrm{~h}$. To correctly resolve the vertical MABL structure, the low computational cost of the one-dimensional simulations enables a vertical grid comprising 150 levels with a resolution of $\Delta z=5 \mathrm{~m}$ close to the surface, slightly stretched up to $1 \mathrm{~km}$, and coarser higher up, with $\Delta z=40 \mathrm{~m}$ from 1 to $5 \mathrm{~km}$. A timestep of $30 \mathrm{~s}$ ensures numerical stability by fulfilling the CFL condition.

Table 1 summarizes the tests performed to study the MABL sensitivity to the surface turbulent fluxes, which can either be calculated from the Lion buoy observations (see Fig. 1 for its location) with the COARE algorithm as in the RUN01 and RUN03 cases, or extracted from the AROME-WMED output and averaged over the area of $50 \mathrm{~km} \times 50 \mathrm{~km}$ (see Fig. 1). For the RUN02 case, a constant SST is prescribed and the surface fluxes are calculated by the MESO-NH model with the COARE parametrization. All the tests reveal a strong increase in wind speed over the course of the day from 0600 UTC to 1700 UTC in relation to the reinforcement of the Tramontane flow. However, the fluxes calculated at the Lion buoy (RUN01) are weaker than those produced by the AROME-WMED and MESO-NH models. Moreover, examination of the evolution throughout the day (not shown here) reveals that the intensification of air-sea exchange at the Lion buoy is delayed with respect to the models, as the increase at the buoy becomes significant from around 0600 UTC, whereas it starts at 0000 UTC in the models. These differences can be attributed to the distance between the model area and the buoy, with the latter lying at the eastern edge of the Tramontane flow. The differences observed between the RUN02 and RUN03 cases in the afternoon are related to a lower simulated wind speed by the MESO-NH model with respect to the AROME-WMED model.

The one-dimensional simulations are performed over the whole day starting at 0000 UTC for the prescribed geostrophic wind speed and advection terms for heat and moisture. Figure 6 presents the mean MABL profiles at 1500 UTC for the different scenarios presented in Table 1, which are compared to the profiles measured by the aircraft at the two locations indicated in Fig. 1 at around 1500 UTC and 1600 UTC. Since the surface fluxes calculated at the Lion buoy are too weak to correctly reproduce the air-sea exchanges in the area of the simulation, the MABL simulated in the RUN01 case is too cold and dry (by $2.5^{\circ} \mathrm{C}$ and $1.5 \mathrm{~g} \mathrm{~kg}^{-1}$, respectively) because the underestimated surface heat and moisture fluxes are unable to compensate for the advection of cold and dry air. Similarly, the lower wind speed at the buoy underestimates the surface stress, and the simulated wind-speed profile exceeds that observed. For the RUN02 case, corresponding to the MABL simulated with a prescribed SST, the profiles of wind speed, specific humidity, and potential temperature lie within the interval between the two aircraft profiles. For the RUN03 case, the wind stress extracted from 
Table 1 Summary of the one-dimensional simulations performed with different surface fluxes computed either at the Lion buoy location from local observed parameters, from the MESO-NH model with a SST fixed at $286.1 \mathrm{~K}$, or extracted from the AROME-WMED model forecast and averaged over the forcing area

\begin{tabular}{|c|c|c|c|c|c|c|c|}
\hline \multirow[t]{2}{*}{ Case } & \multirow[t]{2}{*}{ Source } & \multicolumn{2}{|c|}{$L E\left(\mathrm{~W} \mathrm{~m}^{-2}\right)$} & \multicolumn{2}{|l|}{$H\left(\mathrm{~W} \mathrm{~m}^{-2}\right)$} & \multicolumn{2}{|l|}{$\tau\left(\mathrm{Nm}^{-2}\right)$} \\
\hline & & 0600 UTC & 1700 UTC & 0600 UTC & 1700 UTC & 0600 UTC & 1700 UTC \\
\hline RUN01 & Lion Buoy & 48 & 374 & 12 & 213 & 0.01 & 1.29 \\
\hline RUN02 & MESO-NH & 182 & 410 & 67 & 220 & 0.24 & 1.34 \\
\hline RUN03 & AROME-WMED & 150 & 513 & 57 & 266 & 0.14 & 1.72 \\
\hline
\end{tabular}

All fluxes are computed using the COARE algorithm (Fairall et al. 2003). Values of latent heat, sensible heat and momentum fluxes $(\tau)$ are presented at 0600 UTC and 1700 UTC on 13 March 2013

(a)

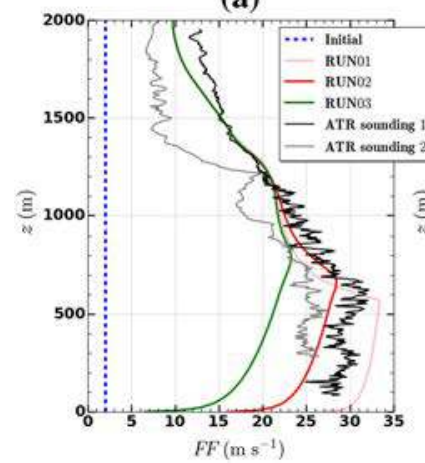

(b)

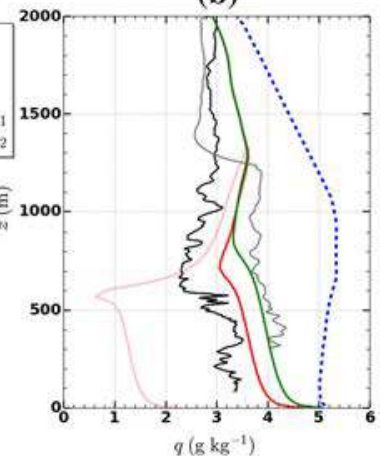

(c)

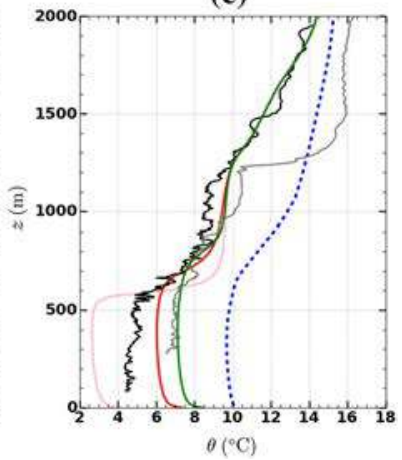

Fig. 6 One-dimensional-simulated profiles at 1500 UTC of a wind speed (FF), b specific humidity $q$, and $\mathbf{c}$ potential temperature $\theta$. The dashed blue line shows the initial profile at 0000 UTC, black and gray lines are the aircraft profiles around 1500 UTC and 1600 UTC, respectively, and the different cases are summarized in Table 1

the AROME-WMED model exceeds that calculated by the MESO-NH model, which leads to an underestimation of the wind speed by up to $5 \mathrm{~m} \mathrm{~s}^{-1}$. As explained above, the horizontal advection of momentum cannot be taken into account by the MESO-NH model. Even though the flow is quite homogeneous (see Fig. 1), the misrepresentation of the momentum advection can be partially responsible for the wind-speed underestimation.

The results of the sensitivity tests performed for different atmospheric and surface forcings led us to choose the RUN02 case as the reference configuration because the mean vertical MABL structure matches the observations well. 


\section{Validation of the Large-Eddy Simulation}

\subsection{Set-Up}

The dimensions of the horizontal domain of the LES model of $25 \mathrm{~km} \times 10 \mathrm{~km}$, with the long side of the rectangle parallel to the mean MABL wind direction, are consistent with Wyngaard (1983), Sykes and Henn (1989) and de Roode et al. (2004), and allow us to simulate several coherent structures with wavelengths of the order of $2 \mathrm{~km}$ as identified from airborne measurements (Brilouet et al. 2017). The extension of the domain along the wind direction is consistent with the increase in the characteristic scales in this direction, as evident in the anisotropy of the turbulent field (Brilouet et al. 2017). Moreover, some hypotheses have been made in order to run the LES model. The large-scale-forcing profiles are applied homogeneously to each vertical column of the domain, which assumes that these forcing terms do not vary horizontally inside the LES domain. Therefore, while the evolution of the mesoscale structures cannot be explored, our objective is to focus on the organization of the turbulence field inside the MABL and, particularly, the internal structure of the convective rolls. The vertical grid consists of 100 levels with a resolution of $20 \mathrm{~m}$ close to the surface, stretching to $70 \mathrm{~m}$ at $1 \mathrm{~km}$, and fixed at $70 \mathrm{~m}$ up to $6 \mathrm{~km}$. The lateral boundary conditions are cyclic, and an absorbing layer is added at the top of the domain to prevent the reflection of gravity waves.

A fundamental criterion for an LES run to qualify as such is that the major part of the turbulent structures must be explicitly resolved, with the number of resolved eddies decreasing as the size of the horizontal mesh increases (de Roode et al. 2004; Honnert et al. 2011). Pope (2000) defines a criterion as $>70-80 \%$ of the total TKE to be explicitly resolved by the LES model. We thus performed three simulations with isotropic horizontal resolutions of 500, 250 and $100 \mathrm{~m}$, which are presented in Fig. 7 in terms of the ratio of resolved TKE to total TKE. Regardless of the resolution considered, the structures are satisfactorily resolved above $700 \mathrm{~m}$, whereas the turbulence is mainly parametrized below $200 \mathrm{~m}$. This poor resolution of the turbulence in the lowest layers has already been highlighted in previous studies (Sullivan et al. 2003; Brasseur 2010; Sullivan and Patton 2011), and is related to the reduced size of the eddies near the surface, which occupy the subgrid domain. Moreover, the choice of the horizontal resolution can be related to the MABL depth. As highlighted by de Roode et al. (2004), the order of magnitude of the characteristic horizontal thermodynamic scales is close to the MABL depth. The one-dimensional reference simulation (RUN02) exhibits a MABL depth of around $700 \mathrm{~m}$ (Fig. 6) and, in the 200-700-m layer, the configuration with a horizontal resolution of $100 \mathrm{~m}$ gives a resolved ratio $>80 \%$. As the structures of interest are thus adequately resolved for $z>0.3 z_{i}$, the results presented hereafter are based on the 100-m LES resolution.

The LES model is initialized with horizontally homogeneous profiles of velocity, specific humidity, and potential temperature derived from the one-dimensional RUN02 simulation at 1200 UTC. The turbulence is initiated with white noise applied to the potential-temperature field at the beginning of the simulation. The duration of the simulation must, therefore, be long enough to obtain a realistic turbulence field (Guichard and Couvreux 2017) based on the large-eddy timescale $t_{*}=z_{i} / w_{*}$ (where, according to Deardorff (1970), $w_{*}$ is the convective velocity scale) representing the time scale of an air parcel transported across the whole MABL at the speed $w_{*}$. The criterion commonly used (Agee and Gluhovsky 1999; Sullivan and Patton 2011) is a duration of $15-20 t_{*}$, which corresponds to a total duration of $2 \mathrm{~h}$ here. The simulation is, therefore, run from $1200 \mathrm{UTC}$ to $1700 \mathrm{UTC}$, implying valid 
Fig. 7 Ratio of the resolved TKE to the total (resolved plus subgrid-scale) TKE for three horizontal resolutions: $\Delta x=500 \mathrm{~m}, \Delta x=250 \mathrm{~m}$ and $\Delta x=100 \mathrm{~m}$. The profiles are horizontally averaged over the simulation area and time-averaged between 1630 UTC and 1700 UTC

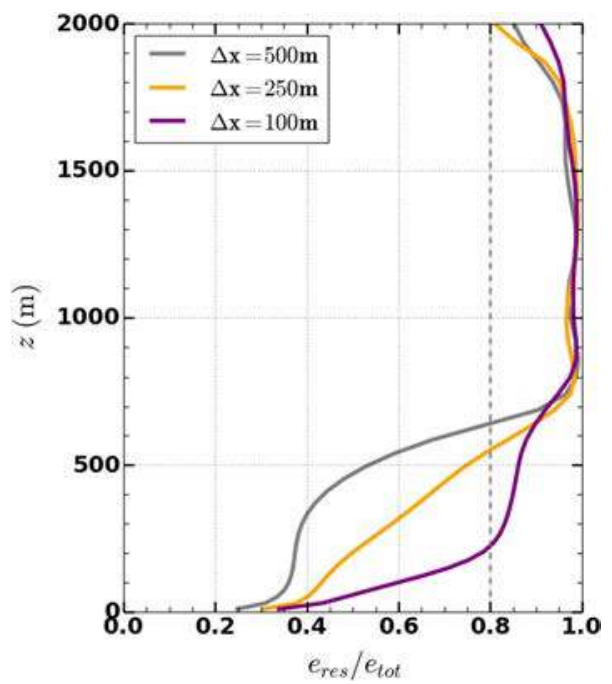

profiles in the interval 1400-1700 UTC. To ensure numerical stability given the high wind speeds $\left(30 \mathrm{~m} \mathrm{~s}^{-1}\right.$ in the MABL), the horizontal resolution of $100 \mathrm{~m}$ requires a timestep of $1 \mathrm{~s}$ to fulfil the CFL condition.

\subsection{Mean Vertical Structure}

The full range of wind-speed, potential-temperature, and specific-humidity profiles in the time interval 1500-1600 UTC and their corresponding mean profiles averaged over the horizontal domain, are presented in Fig. 8, together with profiles from the one-dimensional simulation at 1600 UTC and derived from the aircraft measurements. Compared with the difference between the two observed profiles separated in both time and location, the variability of the simulated profiles over the whole domain and during a 1-h interval of the simulation is of the same order of magnitude for the three parameters. All mean one-dimensional and LES profiles are in the range of the observed profiles, except for specific humidity whose magnitude is too high in the layer 1300-1900 m, but with a negligible impact on the representation of the MABL turbulence. The values of the one-dimensional profiles are found within the full range of the individual LES profiles. With a horizontal resolution of $100 \mathrm{~m}$, the surface layer is parametrized and cannot be explicitly resolved. As the main drivers of MABL evolution are the surface fluxes determined from a bulk algorithm, the mean thermodynamic characteristics of the one-dimensional simulation and the LES model are similar. The slight differences appearing above the surface layer result from the vertical transport and the distribution of the energy inside the MABL, which leads to a more mixed layer for the LES model than for the one-dimensional simulation. The MABL depth $z_{i}=750 \mathrm{~m}$, which is defined here as the level at which potential temperature, specific humidity, and momentum depart sharply from their average values in the mixed layer below. Since the value of $z_{i}$ deduced from the two aircraft profiles (see Sect. 2.1.2) separated by around $70 \mathrm{~km}$ and $1 \mathrm{~h}$ is $600-700 \mathrm{~m}$, the mean MABL structure is very well simulated. 
(a)

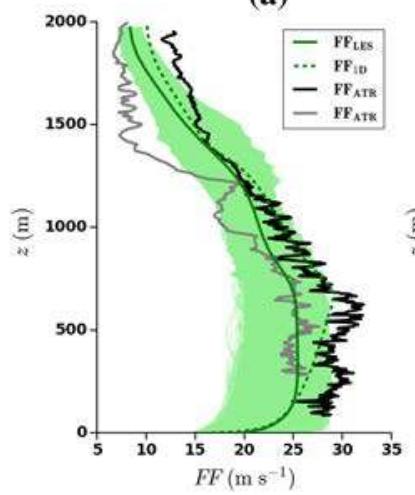

(b)

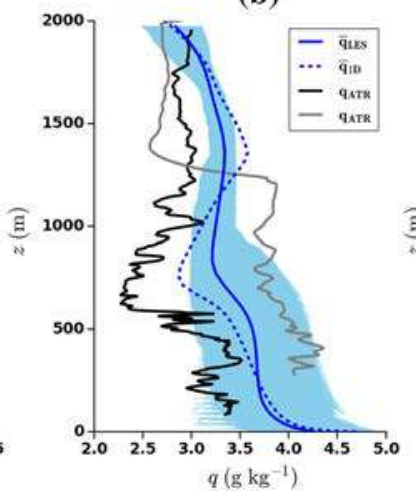

(c)

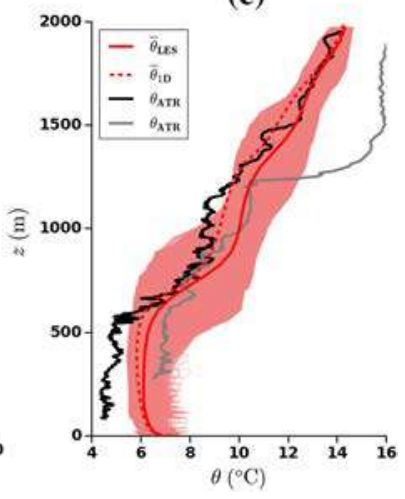

Fig. 8 Mean profiles of a wind speed $(F F)$, b specific humidity $q$, and $\mathbf{c}$ potential temperature $\theta$ averaged in the LES domain between 1500 UTC and 1600 UTC (solid lines), and from the one-dimensional simulation at 1600 UTC (dashed lines). The coloured zones represent the full range of individual LES profiles over the domain between 1500 UTC and 1600 UTC. Black and gray lines are the aircraft profiles around 1500 UTC and 1600 UTC, respectively

\subsection{Turbulent Fluxes}

Figure 9 presents the LES profiles of momentum, and kinematic heat and moisture fluxes averaged between 1600 UTC and 1630 UTC, which are representative of the quasi steadystate conditions encountered from 1500 UTC to 1700 UTC when the CAO event is well established. The decomposition of the profiles into subgrid and resolved contributions illustrates that the surface layer is completely parametrized and that the resolved contribution becomes significant at $z=100 \mathrm{~m}$ and predominant for $z>200 \mathrm{~m}$. The simulated profiles are compared to observed covariances determined from turbulence measurements sampled on aircraft legs at several heights. A correction method has been applied to the airborne measurements to reduce the errors linked to sampling issues and data processing (see Brilouet et al. 2017 for details). Linear interpolation through the mean and standard deviation values of the covariance give an estimation of the air-sea exchange by extrapolation to the surface within a certain confidence interval. Due to the high wind speeds and the orientation of the wind direction along the larger axis of the domain, the vertical transport of momentum is mostly governed by the term $\overline{w^{\prime} u^{\prime}}$ (the fluctuation $u^{\prime}$ being aligned with the long axis of the domain). The momentum- and heat-flux profiles fit the observations, while the surface values derived from the COARE algorithm match the observations well. The moisture-flux profile decreases continuously from the surface to the top of the MABL, where it falls to very low values because of the weak moisture gradient observed at the transition between the MABL and the lower free troposphere. The radiosonde profiles (not shown) launched on the shoreline north of the simulation area show the temperature jump is well marked at the top of the mixed layer, whereas the transition towards dry layers is shifted higher by several hundred metres.

The latent-heat-flux deficit amounts to $\approx 280 \mathrm{~W} \mathrm{~m}^{-2}$ with respect to the observations, exceeding the uncertainty in the observations, and may echo the discrepancy raised by Brilouet et al. (2017) who compared bulk fluxes computed with the COARE algorithm at the Lion buoy with airborne-flux measurements. Therefore, either the high wind speeds are 
(a)

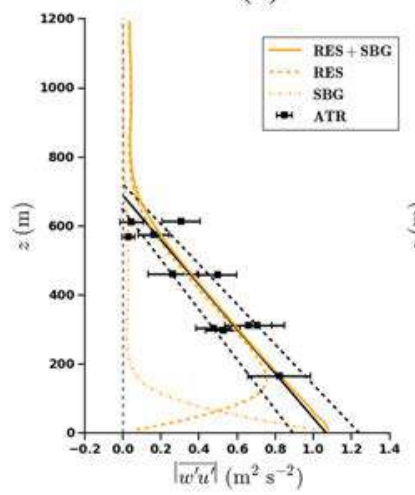

(b)

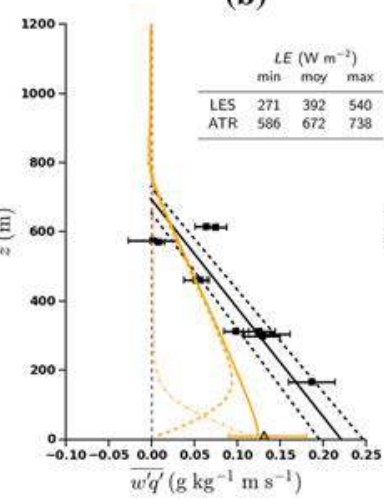

(c)

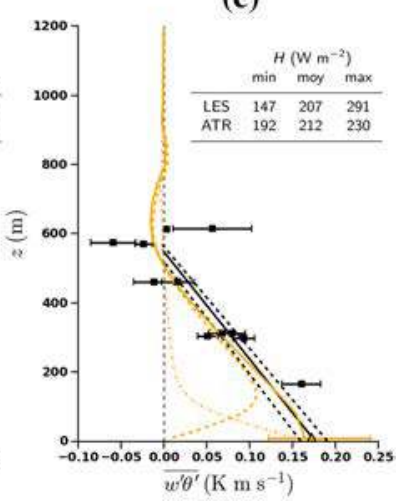

Fig. 9 Profiles of a momentum flux $\left|\overline{w^{\prime} u^{\prime}}\right|$, $\mathbf{b}$ moisture flux $\overline{w^{\prime} q^{\prime}}$, and $\mathbf{c}$ kinematic heat flux $\overline{w^{\prime} \theta^{\prime}}$, averaged between 1600 UTC and 1630 UTC from the LES model (orange); the solid lines are the total flux (resolved and subgrid parts), and the resolved and subgrid contributions are the dashed and dotted lines, respectively. The squares represent the flux values from airborne measurements, solid and dashed black lines are linearly interpolated profiles through the flux values (squares) and the extremities of the error bars, respectively, as detailed in Brilouet et al. (2017). The tables in (b) and (c) indicate the values of observed and simulated surface fluxes. The "min" and "max" LES surface fluxes represent the range of the values simulated in the period $1600-1630$ UTC

beyond the validity of the COARE algorithm or there is an erroneous value in one or several parameters used in the algorithm with respect to the wind speed and/or specific humidity.

As reported in Table 1, the latent heat flux extracted from the AROME-WMED model, which is also computed with the COARE algorithm, is $100 \mathrm{~W} \mathrm{~m}^{-2}$ higher than that computed by the MESO-NH model, and is mainly explainable by a wind speed $5 \mathrm{~ms}^{-1}$ higher in the AROME-WMED model than in the MESO-NH model, with the latter being close to the lower bound of the observational range, as remarked in Sect. 4.2. However, the latent heat flux from the AROME-WMED model still remains underestimated by nearly $160 \mathrm{~W} \mathrm{~m}^{-2}$.

An underestimation of the prescribed moisture advection would be another possible cause of the difference between the observed and simulated moisture flux, because the advection of dry air tends to reduce the specific humidity in the MABL and, hence, to reinforce the moisture-difference term in the bulk algorithm, thereby increasing the flux. Moisture advection is a combination of the wind speed and the horizontal gradient of specific humidity $(\partial q / \partial x)$ in the wind direction. While the specific-humidity gradient produced by the AROME-WMED model is hard to validate due to the scarcity of observations on the domain, an increase in this term would increase the turbulent flux of moisture.

The underestimation of the latent heat flux may also be due to the uncertainty in bulk formulations at high wind speeds (Brunke et al. 2003). Andreas et al. (2008) note that the COARE algorithm has been fitted to data collected for wind speeds $<20 \mathrm{~m} \mathrm{~s}^{-1}$, and, therefore, extending the parametrization to $>20 \mathrm{~m} \mathrm{~s}^{-1}$ may not be reliable. The parametrization of Moon et al. (2007) would have been an alternative to coping with a possible defect of the COARE algorithm in high wind speeds, as it has been developed for hurricane conditions. While this surface scheme was not available in the MESO-NH model version used here, surface fluxes were calculated with the algorithm of Moon et al. (2007) from the Lion buoy observations during the HyMeX-SOP2 field campaign. Between 1600 UTC and 1700 UTC, the latent heat flux reached $580 \mathrm{~W} \mathrm{~m}^{-2}$, which is $206 \mathrm{~W} \mathrm{~m}^{-2}$ higher than with the COARE algorithm (see Table 1). An analysis of the whole multi-day dataset of the HyMeX-SOP2 field campaign 
(not shown here) confirms this tendency, with systematically higher estimates of the surface fluxes with the algorithm of Moon et al. (2007) with respect to other parametrizations, such as the COARE or ECUME algorithms.

There is the possibility that the "classic" bulk formulations do not take into consideration all the physical processes occurring at the surface and in the surface layer and that the contribution of sea spray may be missing (e.g. Andreas et al. 2008, 2015). Andreas et al. (2008) estimate the sea-spray contribution to account for at least $10 \%$ of both sensible and latent heat fluxes for wind speeds $>12 \mathrm{~m} \mathrm{~s}^{-1}$ and may even be larger for higher wind speeds. For our case study, the ATR42 flight report of 13 March 2013 states that there were many whitecaps at the surface, and that the pilots were forced to limit the duration of the lowest flight altitude due to a high amount of sea spray reducing visibility and depositing sea salt on the cockpit window. As pointed out in the review of Emanuel (2018), the potential impact of the sea spray on air-sea exchange is an increasing concern in the air-sea interaction community.

Another possible cause lies in the particular organization of the turbulence field into coherent structures, which could even have an impact on surface-layer processes and therefore on surface fluxes. The bulk formulation is based on MOST, requiring stringent hypotheses, such as homogeneity and stationarity of the turbulence field as well as a flat uniform surface. Nonetheless, MOST exhibits some limitations as emphasized by Sun et al. (2016), who describe a conceptual framework- the so-called hockey-stick transition-which distinguishes the local mixing produced by wall-attached eddies (Townsend 1961) from the large-scale non-local exchange due to coherent structures. Moreover, Li et al. (2018) highlighted the impact of the coherent structures inside the surface layer on the modulation of small-scale structures (wall-attached eddies). The impact of turbulence organization is not currently taken into account in bulk formulations, and MOST may be too simple to fully describe complex conditions at the sea surface, such as for swell (e.g. Smedman et al. 2009).

\section{Turbulence Organization}

\subsection{Cross-Sections of the Simulated Fields}

The organization of the turbulence field into coherent structures is investigated by inspection of horizontal cross-sections of the fluctuations of the vertical velocity component and specific humidity (obtained by removing the horizontally-averaged value) as presented in Fig. 10 at three heights in the MABL $\left(z / z_{i}=0.4,0.6\right.$ and 0.8$)$. The turbulence field is clearly anisotropic, with well-defined coherent structures elongated along the wind direction and characterized by a regular alternation of positive and negative values of fluctuations. This translates as an organization into convective rolls whose longitudinal axis is close to the wind direction, which is consistent with previous numerical studies, such as those of Liu et al. (2004) and Park et al. (2016) who identified aligned rolls with the mean wind direction, and Gryschka and Raasch (2005) who found an angle of $30^{\circ}$ between the coherent-structure axis and the geostrophic wind direction. Such cross-sections reveal an organization into coherent structures: the areas of positive vertical velocity component are identical at the three levels, and are associated with positive moisture fluctuations, whose cross-sections indicate structures growing with altitude. At the upper level, the structures in the specific-humidity fluctuations appear more organized than those below, with wider areas of large fluctuations (positive and negative), which is consistent with previous numerical studies (Jonker et al. 1999; de Roode et al. 2004; Couvreux et al. 2005), and highlights the complex processes 
(a)

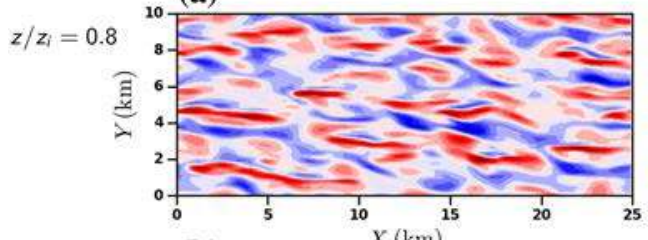

(b)

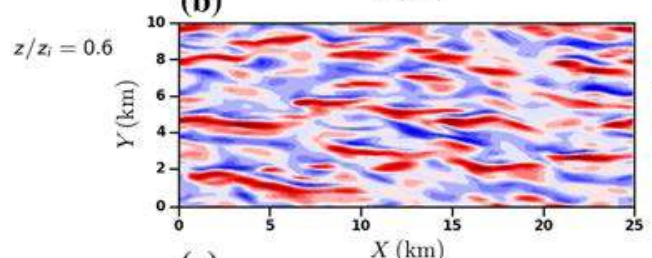

(c)
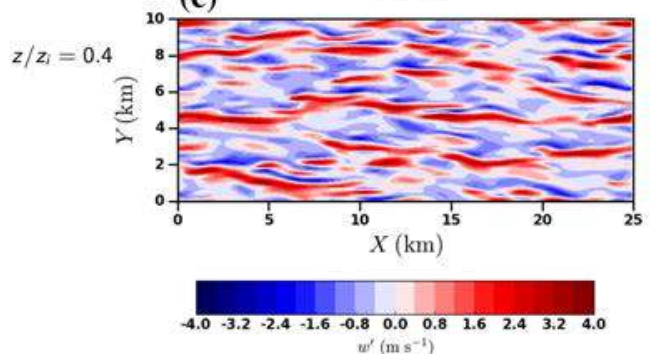

(d)

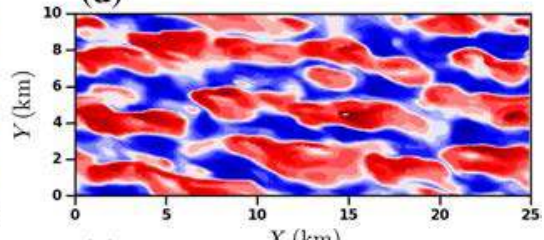

(e)

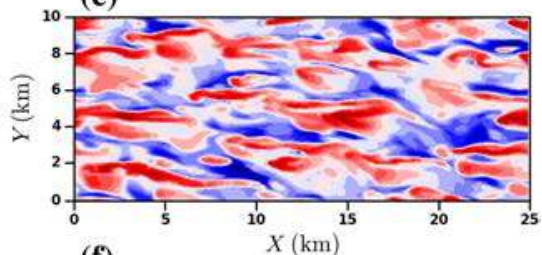

(f)

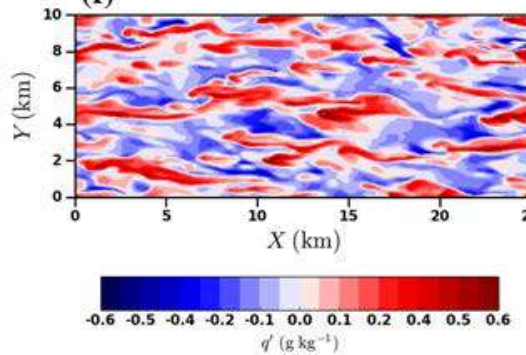

Fig. 10 Horizontal cross-sections at 1545 UTC of fluctuations of the vertical velocity component $w^{\prime}$ (left panels) and specific humidity $q^{\prime}$ (right panels) at three normalized heights: $z / z_{i}=0.8$ (a and $\mathbf{d}$ ); $z / z_{i}=0.6$ (b and $\mathbf{e}) ; z / z_{i}=0.4(\mathbf{c}$ and $\mathbf{f})$

involved in the moisture evolution, such as convective activity, synoptic contributions, and entrainment. Coherent structures are also observed in the fields of potential-temperature fluctuations (not shown here), but not as obviously as in the moisture fluctuations since warmer air parcels originate from either the surface or the top of the MABL, thus complicating the temperature field even in the presence of organized structures.

Figure 11 presents vertical cross-sections of the fluctuations of the vertical velocity component, and the potential-temperature and moisture fluctuations with respect to the average over the horizontal fields at each level in and perpendicular to the mean wind direction. The organization into rolls results in large differences depending on the observation direction. The structures are particularly clear in the crosswind section in the upper part of the MABL, with almost three pairs of counter-rotating cells. As expected, the signs of the fluctuations of temperature and moisture are opposite in this area, but there is a phase shift in the fluctuations of the vertical velocity component, because of the slanted or even horizontal perspective of the roll helical circulation. This organization is reminiscent of the structure observed in the aircraft data (see Fig. 3), with characteristic scales of the same order for the observations $\left(2400 \mathrm{~m}\right.$ ) and simulations (around $3000 \mathrm{~m}$ ). With observed and simulated MABL heights $z_{i}$ of $600-700 \mathrm{~m}$ and $750 \mathrm{~m}$, respectively (cf. Sect. 4.2), the aspect ratios $\lambda / z_{i}=4$ (i.e. the ratio of the wavelength to the ABL depth) for the simulated MABL and $\lambda / z_{i}=3.4-4$ for that observed, which is in agreement with that observed in convective rolls during a previous CAO event (Renfrew and Moore 1999) and numerical studies (e.g. Liu et al. 2004; Gryschka and Raasch 2005). In the along-wind cross-section, there is no clear and regular organization, 
(a)

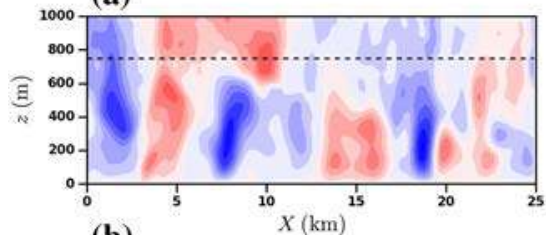

(b)

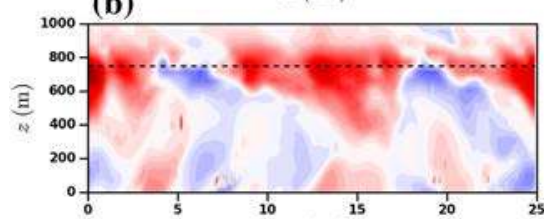

(c)

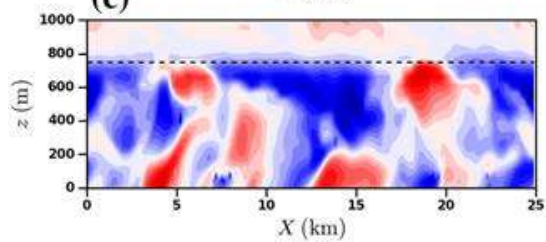

(d)

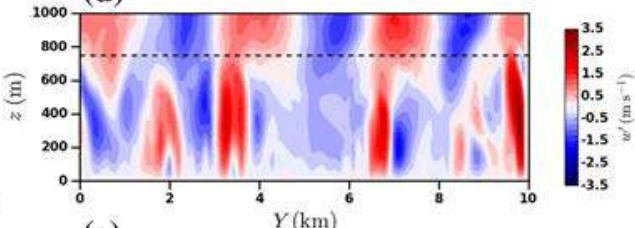

(e)

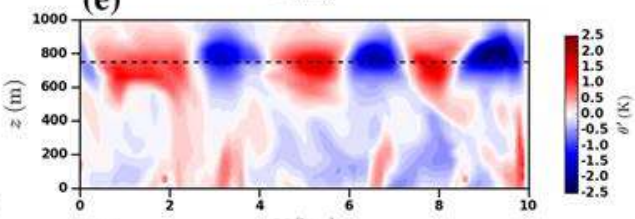

(f)

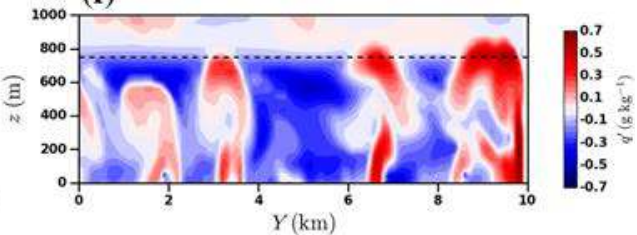

Fig. 11 Vertical cross-sections at 1630 UTC along the mean wind direction at $Y=5 \mathrm{~km}$ (left panels) and perpendicular to the mean wind direction at $X=12.5 \mathrm{~km}$ (right panels): fluctuations of the vertical velocity component $w^{\prime}$ (a and d); potential-temperature fluctuations $\theta^{\prime}$ (b and e); specific-humidity fluctuations $q^{\prime}$ (c and $\mathbf{f})$. The dashed line in each panel refers to the MABL depth $\left(z_{i}=750 \mathrm{~m}\right)$

though in the upper half of the MABL, it appears that the central part of the section (between 8 and $17 \mathrm{~km}$ on the horizontal axis) lies in the descending branch of the rolls, which results in warmer and drier air parcels. Above the MABL, fluctuations remain significant, which may be the signature of internal gravity waves generated by the boundary-layer rolls (Lane and Clark 2002; Melfi and Palm 2012; Thurston et al. 2016).

\subsection{Evaluation with Respect to Observations}

The organized features simulated here are consistent with aircraft observations reported by Cook and Renfrew (2015) and Brilouet et al. (2017) who identified an elongation of the turbulent eddies in the along-wind direction, which is more pronounced in unstable conditions, as well as evidence of increasing scales with height. The anisotropy of the turbulent field can be illustrated by presenting values along two orthogonal directions at the same level from the LES results as presented in Fig. 12a-c for the vertical velocity component, and the temperature and moisture through the along-wind and crosswind directions of 9-km length at the height $z / z_{i}=0.4$. As expected, the along-wind signal contains much less information than the crosswind one, with no clear signs of organization. Convective rolls are three-dimensional structures that cannot be fully characterized with unidirectional sampling. Furthermore, the crosswind samples can be compared to the straight and level aircraft runs performed crosswind in the MABL. In order to make the comparison meaningful, we reduced the aircraft series to the same resolution as the LES data $(100 \mathrm{~m})$ by non-overlapping averaging. Though we cannot expect a point-to-point agreement between the observations and simulations given the chaotic nature of the turbulence, we can evaluate whether the characteristic scales and the order of magnitude of the fluctuations are comparable. As can be seen in Fig. 12d-f, the 

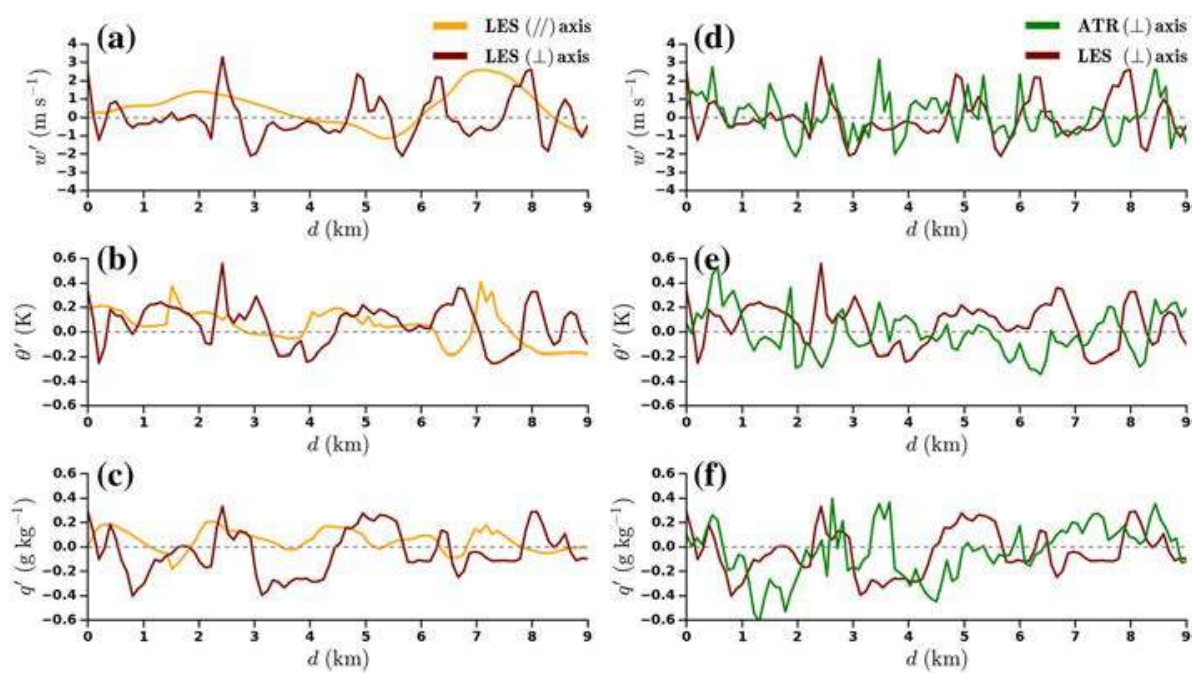

Fig. 12 The fluctuations of the vertical velocity component $w^{\prime}$, potential temperature $\theta^{\prime}$, and specific humidity $q^{\prime}$ at the height $z / z_{i}=0.4$. The left panels correspond to LES samples along $(/ /$, orange) or perpendicular ( $\perp$, brown) to the mean wind direction. The right panels correspond to the crosswind LES data (brown) or measured by the aircraft (green)

observed and simulated series are consistent, which validates the LES results to a degree rarely achieved until now.

The LES results may be evaluated with respect to the observations through statistical parameters such as probability density functions (p.d.f.) or spectral analysis. Figure $13 \mathrm{com}-$ pares the observed and simulated vertical velocity component, potential temperature, and specific humidity at three heights in the MABL, with the LES p.d.f. calculated over the overall horizontal cross-section, and the airborne data averaged over 100-m intervals. In the lower half of the MABL, the simulated vertical velocity component and potential temperature p.d.f. compare well to the observed p.d.f. Their distributions are slightly positively skewed, with a negative mode in the middle of the MABL (but more marked in the vertical velocity component) which is a characteristic of convective regimes (Caughey et al. 1983; Deardorff and Willis 1985). In the middle of the MABL, the turbulence is mostly generated by buoyancy effects or by the vertical transport of turbulence produced at a lower level. Nevertheless, some discrepancies in the vertical velocity component and potential temperature p.d.f. appear at the height $z / z_{i}=0.8$, where the turbulence intensity is underestimated, and may be due either to an overly large decrease in turbulence production or overly strong dissipative effects.

The simulated specific humidity significantly differs from the observed p.d.f. Though the general shape can be regarded as similar in terms of the peak position and skewness, the main discrepancies throughout the MABL lie in a wider range of observed values, which is consistent with the larger measured values of the moisture fluxes. Nevertheless, the p.d.f., once normalized by the standard deviation (not shown here), becomes consistent between the observations and the LES results. As the range of humidity fluctuations observed by the aircraft is wider, the standard deviation is higher and the normalization leads to comparable distributions. This confirms the fact that the structure of the simulated MABL is consistent with that observed in terms of depth, internal organization into coherent structures, and turbulence level, in spite of the underestimated surface moisture flux (evaporation). 

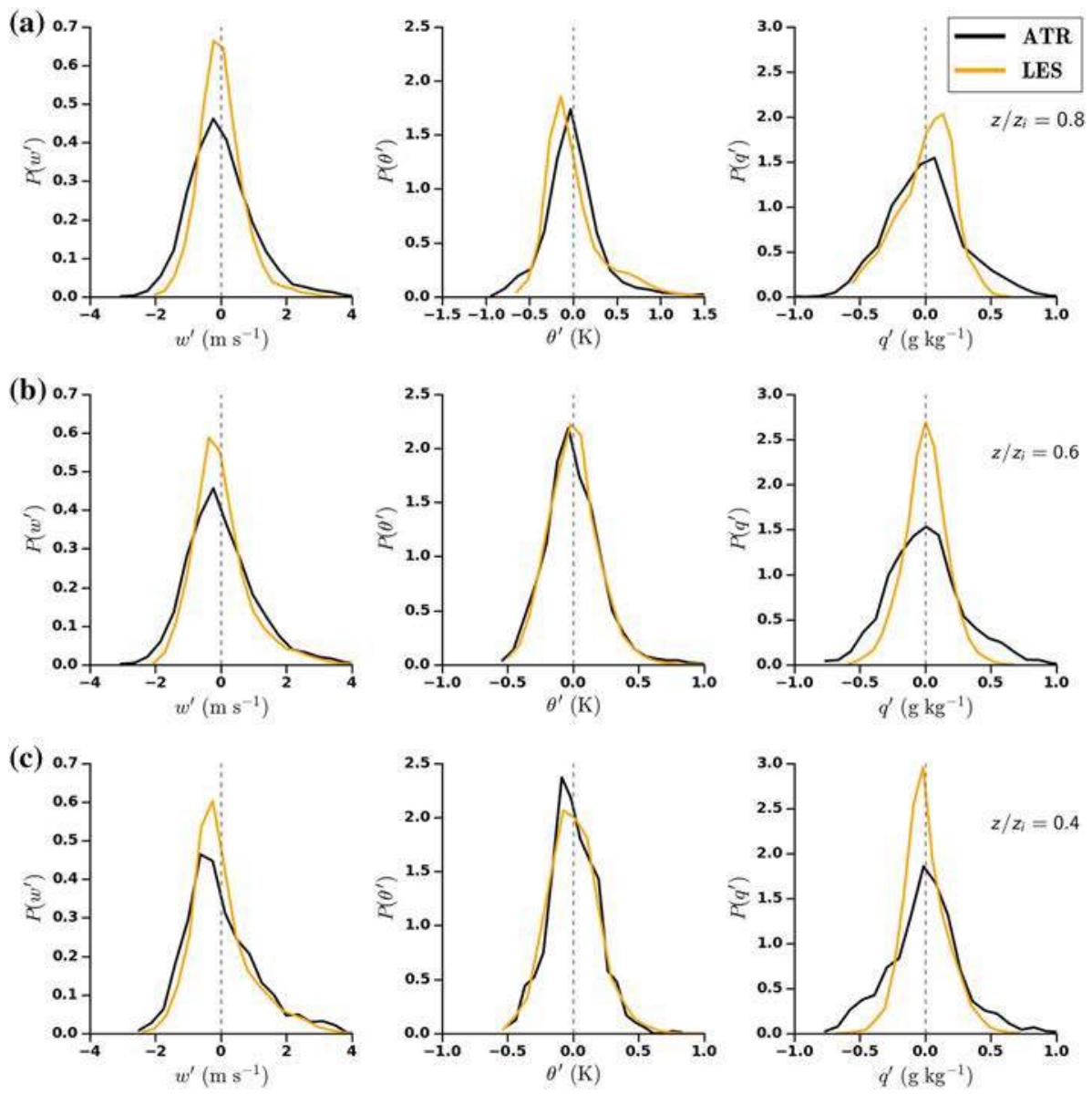

Fig. 13 Probability density functions of the vertical velocity component (left), potential temperature (middle), and specific humidity (right) at the heights $\mathbf{a} z / z_{i}=0.8, \mathbf{b} z / z_{i}=0.6$ and $\mathbf{c} z / z_{i}=0.4$. The orange lines are the LES p.d.f. calculated on horizontal cross-sections at 1630 UTC, and the black lines are computed from the airborne measurements between 1500 UTC and 1730 UTC and averaged at a horizontal resolution of $100 \mathrm{~m}$

The two main sources of MABL turbulence are momentum and buoyancy surface fluxes, which are both simulated well here. The buoyancy source is expressed through the surface sensible heat flux, and, to a lesser degree, the surface latent heat flux whose respective contributions to the total surface buoyancy flux $\left(B_{0}=\overline{w^{\prime} \theta_{v}^{\prime}}\right.$, where $\theta_{v}$ is the virtual potential temperature) of the kinematic heat flux and the moisture flux can be computed as

$$
\left.B_{0} \approx \overline{w^{\prime} \theta^{\prime}}\right|_{0}+\left.0.61 T_{0} \overline{w^{\prime} q^{\prime}}\right|_{0}=\frac{H}{\rho_{0} C_{p}}+0.61 T_{0} \frac{L E}{\rho_{0} L},
$$

where the subscript 0 refers to the surface value, $T$ is the temperature $(\mathrm{K}), \rho$ is the air density, and $C_{p}$ is the specific heat of air at constant pressure $\left(\mathrm{J} \mathrm{kg}^{-1} \mathrm{~K}^{-1}\right)$. Referring to the values of $H$ and $L E$ indicated in Fig. 9 , then $B_{0, \text { obs }} \approx 0.216 \mathrm{~K} \mathrm{~m} \mathrm{~s}^{-1}$ for the observations $\left(0.177 \mathrm{~K} \mathrm{~m} \mathrm{~s}^{-1}\right.$ from the heat flux contribution and $0.039 \mathrm{~K} \mathrm{~m} \mathrm{~s}^{-1}$ from the moisture flux contribution) and $B_{0, \mathrm{LES}} \approx 0.195 \mathrm{~K} \mathrm{~m} \mathrm{~s}^{-1}$ for the LES results $\left(0.172 \mathrm{~K} \mathrm{~m} \mathrm{~s}^{-1}\right.$ from the heat flux contribution 
and $0.023 \mathrm{~K} \mathrm{~m} \mathrm{~s}^{-1}$ from the moisture flux contribution). Hence, the inaccurate value of the buoyancy connected to the underestimation of the latent heat flux amounts to only $10 \%$ of the total buoyancy, and, therefore, does hinder the satisfactory simulation of the MABL turbulence structure.

The observed and simulated spectra reveal the characteristic scales of the coherent structures. Figure 14 shows the spectra (normalized by the variance) of the vertical velocity component, potential temperature, and specific humidity at three heights in the MABL. The simulated spectra are computed at 1630 UTC in the LES results, and consist of the average of individual spectra determined in the cross-wind direction (i.e. along the $Y$-axis of the model). The airborne spectra are computed on the straight and level cross-wind runs from the time series sampled every $0.04 \mathrm{~s}$, which corresponds to a horizontal resolution of approximately $4 \mathrm{~m}$. Observed and simulated spectra are both represented in terms of the wavenumber $k$, with $k=2 \pi / \lambda$ for the LES data ( $\lambda$ being the horizontal wavelength), and $k=2 \pi f / V_{\text {true }}$ for the aircraft data, where $f$ is the frequency in the aircraft time frame, and $V_{\text {true }}$ is the aircraft mean true airspeed over the run $\left(V_{\text {true }} \approx 100 \mathrm{~m} \mathrm{~s}^{-1}\right)$. In contrast to the aircraft data, the LES data are unable to reproduce the inertial (or energy cascade) subrange characterized by a $-2 / 3$ slope, not only because of the limited horizontal resolution $(100 \mathrm{~m})$, but also because of the numerical dissipation inherent to the advection scheme used in the MESO-NH model (Skamarock 2004; Ricard et al. 2013). While this problem may be treated, such as in dedicated LES models (Sullivan et al. 1994) which can even compute spectra in the inertial subrange (Darbieu et al. 2015), its simulation is not crucial here, since the characteristic scales of the convective rolls do not occupy the inertial subrange. Similarly, the eddies contributing to the turbulent fluxes also do not belong to the inertial subrange, and the spectral attenuation observed in the LES results does not preclude the computation of the resolved part of the fluxes. In the range of turbulent energy production, the simulated and observed normalized spectra agree. The wavenumbers corresponding to the spectral peaks are indicated in the Fig. 14, and generally show agreement between the observations and simulations, with any discrepancy less than a factor of two. The only considerable disagreement is observed for the temperature at $z / z_{i}=0.4$, where the observed spectrum peaks at a wavenumber three times smaller than that simulated. However, the aircraft spectrum exhibits a largely flat shape extending over almost one decade. Estimating the peak from an analytical fit (e.g. Brilouet et al. 2017) rather than simply choosing the highest value would probably have given a value closer to the LES peak. From the spectra presented in the Fig. 14, a characteristic wavelength of around $2400 \mathrm{~m}$ can be estimated.

\subsection{Contribution of Coherent Structures to the Vertical Exchanges}

Conditional sampling is used to quantify the contribution of the coherent structures to the turbulent vertical transport in the simulated fields by identifying and isolating the coherent structures from the environment. In a turbulence field organized into convective rolls, structures are characterized by ascending and descending branches. By analogy with the bivariate technique used by Grossman (1984), the conditional sampling used here to identify ascending regions was developed by Couvreux et al. (2010), and is efficient at identifying the coherent structures from the surface to the top of the MABL, and characterizing organized bottom-up transport. In the LES model, a passive tracer is emitted at the surface, continuously and homogeneously over an area, behaving like a radioactive element, with its concentration decay governed by a time constant. The conditional sampling of the ascending branches relies on the vertical velocity component and the concentration of the passive tracer as 

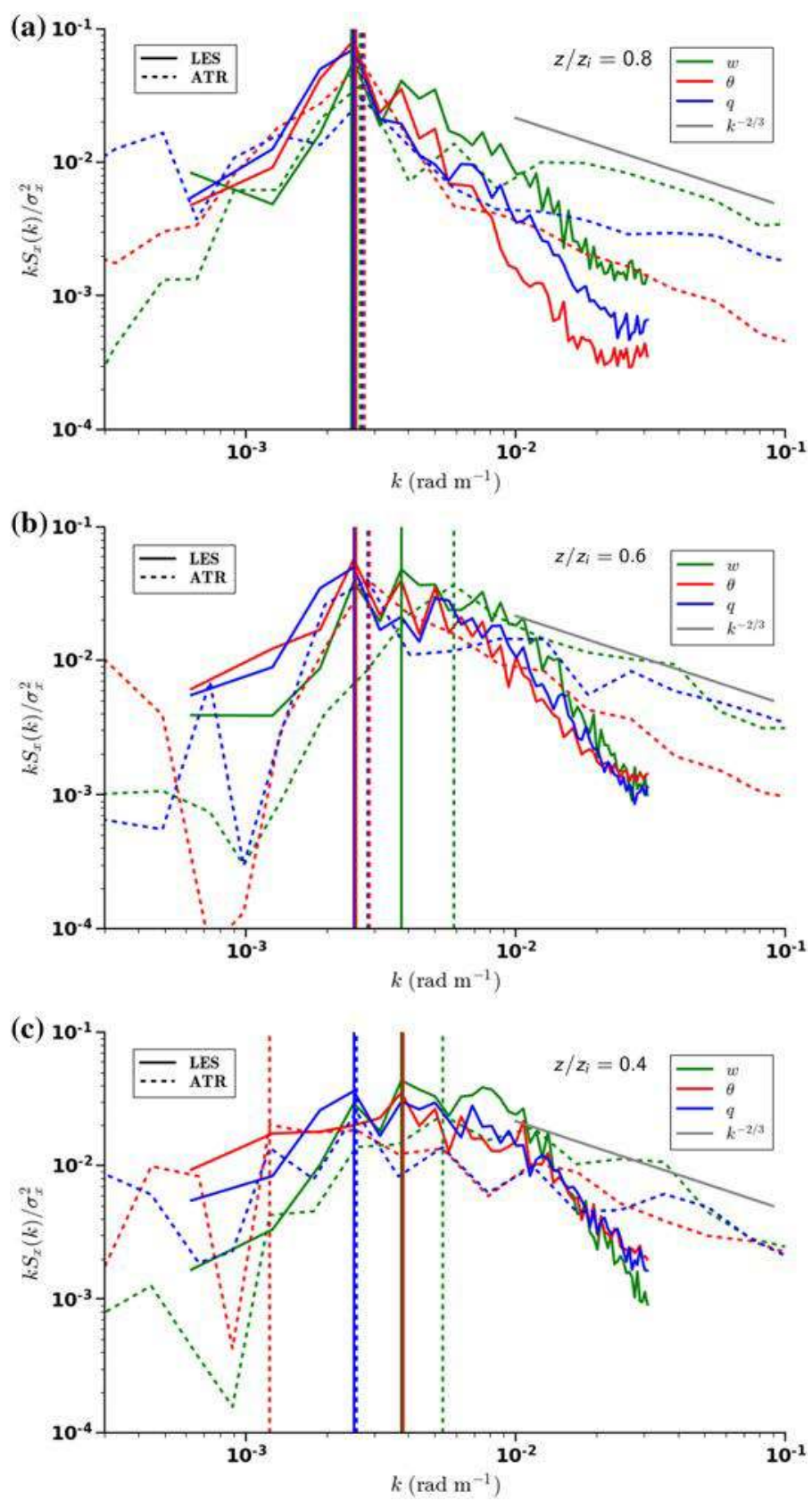

Fig. 14 Normalized energy spectra of the vertical velocity component, potential temperature, and specific humidity at the heights $\mathbf{a} z / z_{i}=0.8, \mathbf{b} z / z_{i}=0.6$, and $\mathbf{c} z / z_{i}=0.4$. The solid lines are the averages of the LES cross-wind spectra computed at 1630 UTC, the dashed lines are the observed spectra computed from cross-wind airborne measurements, and the vertical lines indicate the energy maximum for each spectrum 


$$
x \in \mathrm{UP} \text { if } w^{\prime}>0 \text { and } s v^{\prime}>\max \left(\sigma_{s v}, \sigma_{\min }\right),
$$

with

$$
\sigma_{\min }(z)=\frac{0.05}{z} \int_{0}^{z} \sigma_{s v}(z) \mathrm{d} z .
$$

An air parcel $(x)$ at a given altitude is considered to belong to an ascending branch of a roll if there is a simultaneous positive fluctuation of the vertical velocity component $w^{\prime}$ and a tracer concentration fluctuation $s v^{\prime}$ (relative to the horizontal mean) greater than a given threshold, defined here as the maximum between the standard deviation of the tracer concentration at this altitude $\sigma_{s v}$ and a minimum threshold $\sigma_{\min }$ used to filter low-tracer concentrations. While the descending branches of the rolls could have been sampled from a similar technique with a second passive tracer emitted at the top of the MABL, as performed by Brient et al. (2019) to identify a downdraft, the diagnoses of the descending branches were performed using the specific humidity, as no second passive tracer was emitted in the LES model. The conditional sampling of the descending branches then evaluates the vertical velocity component and the specific humidity as

$$
x \in \mathrm{DOWN} \text { if } w^{\prime}<0 \text { and } q^{\prime}<-\sigma_{q} .
$$

By analogy with the conditional sampling of the ascending regions, an air parcel $(x)$ at a given altitude is considered to belong to a descending branch of a roll if there is a simultaneous negative fluctuation of the vertical velocity component $w^{\prime}$, and a specific humidity fluctuation $q^{\prime}$ smaller than the opposite of the standard deviation of the specific humidity $\sigma_{q}$ at this altitude. The conditional sampling based on the specific humidity is applicable only inside the MABL, and the grid cells identified as descending regions above $z=800 \mathrm{~m}$ have been ignored. While the conditional sampling applied here to identify the coherent structures is related to the characteristic fluctuations of the flow, an alternative approach for isolating the convective rolls from the environment is proposed by Brooks and Rogers (1997) based on spectral partitioning of the organized rolls from the background turbulence.

Figure $15 \mathrm{a}, \mathrm{b}$ presents three-dimensional visualizations of the air parcels identified by the conditional sampling as either ascending or descending branches, with both branches elongated along the mean wind direction with a longitudinal extension reaching $10-15 \mathrm{~km}$, while the transversal scale is around $2 \mathrm{~km}$, which is consistent with the LES analysis above and the airborne observations. As illustrated in Fig. 15c, the fractional areas occupied by the ascending and descending branches are close together, which is consistent with an organization into rolls. The fractional area occupied by the coherent structures, defined as the sum of the ascending and descending branches, is close to 30\%. The maximum is observed just above the surface layer, and the value decreases regularly up to the top of the MABL where it rapidly drops to zero. The profile of the area covered by the updraft portions of the roll structures, always remaining below $17 \%$, is in agreement with previous studies, such as Miao et al. (2006) who found a plume coverage of $21 \%$ as deduced from airborne radar measurements, Shin and Hong (2013) who simulated idealized cases of a convective boundary layer, Chinita et al. (2018) for shallow cumulus cases, and Brosse et al. (2018) who highlighted the impact of thermals on atmospheric chemistry.

Once coherent structures have been identified, it is possible to quantify their contribution to the overall vertical turbulent exchanges. The turbulent flux resolved by the LES model can be decomposed into rising and descending regions whose sum is the coherent-structure contribution (which can be qualified as "non-local" because of the vertical extension of these structures throughout the MABL), with the remaining regions referred to as the environ- 
(a)

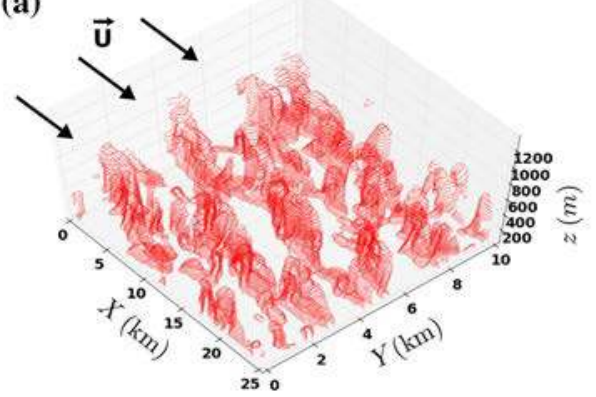

(b)

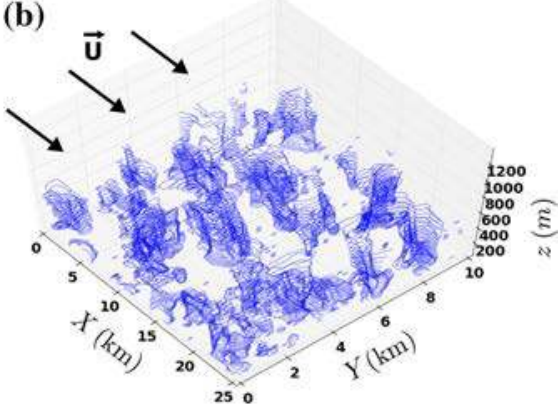

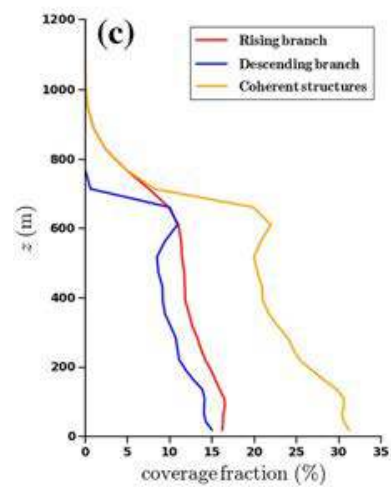
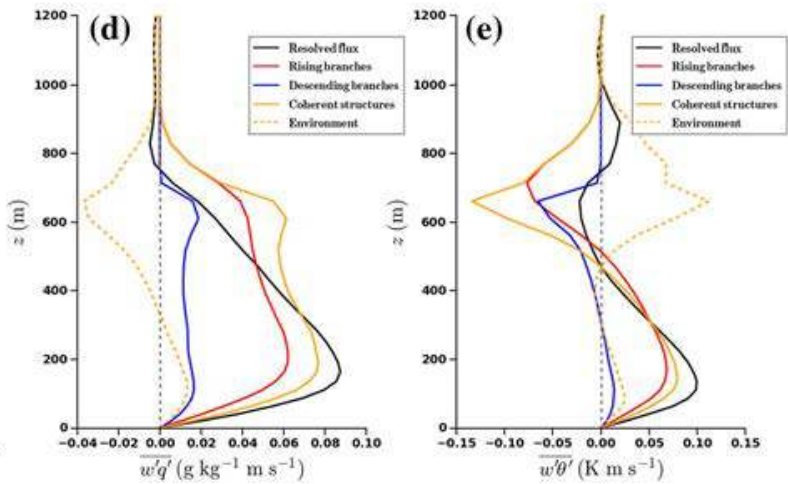

Fig. 15 Three-dimensional visualization of the $\mathbf{a}$ ascending and $\mathbf{b}$ descending branches diagnosed with the conditional sampling at 1545 UTC over the LES domain (see text for details); the black arrows represent the wind direction. Respective contributions of the ascending and descending branches and of the coherent structures defined as the sum of both to $\mathbf{c}$ the fractional area, $\mathbf{d}$ the moisture flux and $\mathbf{e}$ the heat flux. The black lines represent the resolved fluxes, the solid and dashed colour lines the contribution of the coherent structures and of the environment to the resolved flux, respectively

ment. Figure 15d, e shows that the contribution of the coherent structures to the moisture and heat fluxes is predominant in spite of their low fractional area in the whole MABL. Above $z=500 \mathrm{~m}$ and approaching the MABL top, the contribution of the coherent structures and the environment to the resolved kinematic heat flux become almost equal and opposite, with the negative contribution of the coherent structures related to penetrative updrafts. In this entrainment zone, the positive fluctuations of the vertical velocity component are associated with a negative potential-temperature fluctuation because an air parcel transported by a coherent structure arrives in a warmer environment, which is consistent with the interpretations of previous experimental studies (e.g. Young 1988; Chou and Zimmerman 1989). Concerning the moisture flux, the contribution of coherent structures remains positive in the whole MABL. The air parcels transported above by the ascending branches are moister than the environment, and the descending entrained parcels contribute to a positive moisture flux. Furthermore, the vertical transport relative to the convective rolls is mainly supported by the ascending branches, and the contribution of the descending regions is of the same order of magnitude as that of the environment.

This flux partitioning is relevant for CAO events, since the convection inside the MABL is driven by the surface forcings, and the updraft regions contain the most significant contribution to the vertical transport. LeMone (1976) interpreted this non-local transport as the result of the concentration of turbulence-producing eddies by roll circulation. Salesky and 
Anderson (2018) also highlighted the important role of this modulation for turbulent transport in the ABL. The adequate representation of the role played by coherent structures in vertical turbulent exchanges is fundamental to improving atmospheric numerical models, with parametrizations having already been developed to represent non-local transport (Hourdin et al. 2002; Soares et al. 2004; Pergaud et al. 2009). Therefore, the LES approach is a powerful tool for designing parametrizations based on physical processes, for which the present study could be considered the next step towards a better understanding of the MABL processes occurring during $\mathrm{CAO}$ events.

\section{Discussion and Conclusions}

The turbulence characteristics of the MABL in high wind speeds have been analyzed using both airborne measurements collected during the HyMeX field campaign in the north-western Mediterranean basin and a LES model. In Brilouet et al. (2017), a statistical approach on an ensemble of CAO events identified the organization of the turbulence field into longitudinal rolls. As convective rolls cannot be fully characterized with unidirectional aircraft measurements (Lohou et al. 2000; Lothon et al. 2007; Brilouet et al. 2017), the LES approach becomes a versatile tool for fully describing organized structures and quantifying the contribution of the structures to turbulent transfers. We focused on 13 March 2013 when the wind-speed increase began at midnight, reaching around $25 \mathrm{~m} \mathrm{~s}^{-1}$ in the boundary layer during the afternoon, with a high contrast in temperature and moisture between the sea surface and the lower atmosphere over the flight area, and lasting until the next day.

Considering the sparsity and complexities of field campaigns over the sea, the quantity and quality of the in situ data collected during the HyMeX-SOP2 field campaign in the Gulf of Lion in high wind speeds should be noted. In particular, the airborne measurements were crucial in demonstrating the presence of coherent structures, defining their main characteristics, and validating the simulations. The observed high wind speeds and large horizontal gradients entail a strong horizontal advection (of heat and moisture), which must be prescribed for local simulations (one-dimensional or LES model investigations). These forcings were computed from the AROME-WMED model forecasts, the quality of which was evaluated using the airborne observations. The MESO-NH model was first run in single-column mode with this forcing, which enabled determination of the configuration able to satisfactorily reproduce the vertical structure of the MABL. This configuration was used to constrain the LES run in the afternoon during the well-established phase of the CAO event.

The mean thermodynamic characteristics of the simulated MABL with the LES model are in good agreement with the mean structure observed by the aircraft profiles. Turbulent characteristic profiles, such as the momentum and kinematic heat flux, are also consistent with the observations. Moreover, the simulated turbulent field is anisotropic, with stretched eddies aligned along the mean wind directions. Boundary-layer convective rolls as observed in the airborne measurements were successfully simulated with a ratio between longitudinal and transversal extensions reaching 5-7.5 and an aspect ratio of about four. The aircraft observations along the straight and level runs, once reduced to a spatial resolution comparable to that of the LES model, yield a structure comparable to that simulated, which extends the LES validation beyond averaged profiles of the mean quantities or turbulence statistics.

The simulated surface fluxes of heat, moisture and momentum are computed with the COARE algorithm (Fairall et al. 2003) using a constant surface temperature observed at the Lion buoy, and were compared with the values extrapolated to the surface from the 
aircraft flux profiles according to the method described in Brilouet et al. (2017), which enables determination of the uncertainty of the surface values. The agreement between the observed and simulated flux profiles is excellent for the momentum and kinematic heat flux, but the simulation underestimates the moisture flux, with the difference exceeding the sum of the uncertainty of the aircraft value and the variability inside the LES domain. This discrepancy does not affect the MABL structure beyond the moisture fluctuations and the turbulent moisture flux in that the simulated MABL resembles the observations in terms of depth, organization into rolls and cloud cover, turbulence intensity, and the characteristic scales. The reasons for this discrepancy are not known with certainty, but some hypotheses are as follows:

- A one-dimensional simulation was performed in which the surface moisture flux was artificially forced to be consistent with the aircraft measurements. This forcing simulates an excessively thick MABL with a strong entrainment at its top, which is very different from that observed. This artificial enhancement in the surface flux probably breaks the balance between the prescribed advection and turbulent transfer of moisture.

- Therefore, an underestimation of the prescribed moisture advection would be another possible cause of the difference between the observed and simulated moisture flux. The moisture advection is a combination of the wind speed and the horizontal gradient of specific humidity $(\partial q / \partial x)$ in the wind direction. The specific-humidity gradient produced by the AROME-WMED model is hard to validate because of the scarcity of observations within the domain. Increasing this term would reinforce the turbulent moisture flux.

- Another source of error lies in the surface-flux computation of the COARE parametrization. Since the advection of momentum cannot be prescribed in the LES model for technical reasons, the mean wind speed computed by the model is somewhat underestimated, which results in a smaller value of the moisture flux.

- Furthermore, an underestimation of the moisture flux due to the parametrization itself could also be possible, because the high wind speeds of this CAO event are on the threshold, or even beyond the range of model validity. Incidentally, the parametrization proposed by Moon et al. (2007) for hurricane conditions results in considerably higher values for this case $\left(580 \mathrm{~W} \mathrm{~m}^{-2}\right.$ instead of $374 \mathrm{~W} \mathrm{~m}^{-2}$ for the COARE algorithm at the Lion buoy). In high-wind-speed CAO events, organizations are present in both the MABL (convective rolls) and at the sea surface (waves and swell). Furthermore, the breaking of waves injects a large amount of sea spray into the surface layer, which impacts the air-sea exchange. A holistic parametrization of air-sea fluxes should take into account all these processes, including the organized structures in the MABL. Such a parametrization is not yet available, though valuable efforts have been made to involve the role of sea spray (Andreas et al. 2016). The use of the LES approach to address this question would require metre-scale horizontal resolutions to be able to describe the atmosphere-wave interactions.

The explanation for the underestimation of the moisture flux probably lies in a combination of these different factors (weak advection, wind-speed underestimation and incomplete flux parametrization). As a direct consequence of the underestimated moisture flux, the p.d.f. of the specific humidity significantly differs from observations, in contrast to the agreement for the p.d.f. of both the temperature and vertical velocity component with that observed. Nevertheless, once normalized with the standard deviation, the p.d.f. of the simulated specific humidity mimics the observations much better, which confirms that the MABL structure is well simulated, even with a considerable underestimation of the moisture flux. 
To improve diagnoses of the coherent structures in the MABL, and to quantify their contribution to the turbulent transfers, a tracer of specified lifetime was released at the surface in the LES model. Conditional sampling based on the method developed by Couvreux et al. (2010) enables distinguishing the coherent structures from the environment, as well as separating their ascending and descending branches. In the well-resolved part of the MABL domain (i.e. above $200 \mathrm{~m}$ ), the ascending and descending branches cover a similar fractional area (10$15 \%$ ), which is further evidence of the organization into rolls. In spite of their minor fractional area, the contribution to the vertical energy exchanges of the ascending branches is predominant. The resolution of the LES results analyzed does not enable description of the coherent structures at the lowest heights in the boundary layer, which would help to understand their interactions with the exchanges at the sea surface. Here again, a metre-scale-resolution LES model would be required to fully analyze the surface layer.

The main strength of the LES model deployed here is the capture of the organized convection at high wind speeds during a CAO event, and the successful comparison of results with airborne measurements. Care in the processing of airborne-turbulence data described in Brilouet et al. (2017) has enabled the detailed analysis and validation of the LES results, even for the turbulence fields produced by the simulation. In spite of a limited horizontal model resolution $(100 \mathrm{~m})$, which prevents resolution of the turbulent scales in the surface layer, the LES model reproduces the mean and turbulent MABL structure, with the organization of the simulated turbulent field into convective rolls in agreement with the aircraft observations. We were even able to compare the characteristic scales and turbulence spectra. To the best of our knowledge, there are very few similar works. Such works could pave the way to a better understanding of the role played by the convective rolls and to improvements in the mass-flux schemes to better take into account vertical non-local transport.

Acknowledgements Many people were involved in the realization of the aircraft mission of HyMeX-SOP2 and in the data processing. The aircraft was operated by the Service des Avions Français Instrumentés pour la Recherche en Environnement (SAFIRE). We also thank the TRAMM team from CNRM (Centre National de la Recherche Météorologique) at Météo-France for their help in computing the data. This work is a contribution to the HyMeX program (HYdrological cycle in the Mediterranean EXperiment, www.hymex.org) through the ASICS-MED project (Air-Sea Interaction and Coupling with Submesoscale structures in the MEDiterranean), ANR-12-BS06-0003). The authors acknowledge Météo-France for supplying the data and the HyMeX database teams (ESPRI/IPSL and SEDOO/Observatoire Midi-Pyrénées) for their help in accessing the data (accessible on http://mistrals.sedoo.fr/HyMeX/). We also gratefully thank C. Lac, F. Couvreux and T. Bergot for their help with the numerical simulations and M.-N. Bouin (CMM/CRNM) for providing us the buoy-derived bulk fluxes.

\section{Appendix 1: Cloud Cover}

We present here some illustrations of the cloud cover for the period of time during which the observations and simulations were performed. People on board the aircraft reported cloud streets observed at the MABL top. Unfortunately, as the shortwave and longwave broadband radiation sensors installed on the aircraft malfunctioned, we examined satellite observations. Presented in Fig. 16 are photos from the MODIS instrumentation aboard the AQUA and TERRA satellites in the mornings of 13 and 14 March 2013. The meteorological conditions evolved rapidly during 13 March, with a progressive development of the CAO event associated with an increasing wind speed from 0000 UTC to the early afternoon. The MODIS image taken at 1010 UTC exhibits a large cloud cover, which is denser in the southern half of the domain explored by the aircraft. Unfortunately, there is no image available during the afternoon period analyzed here. We might however assume that the cloud cover disaggregated 
(a)

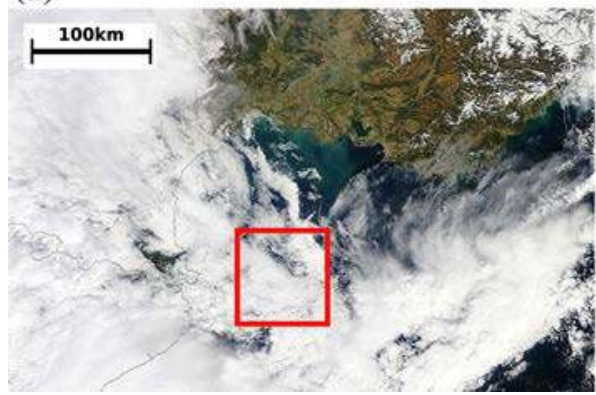

(b)

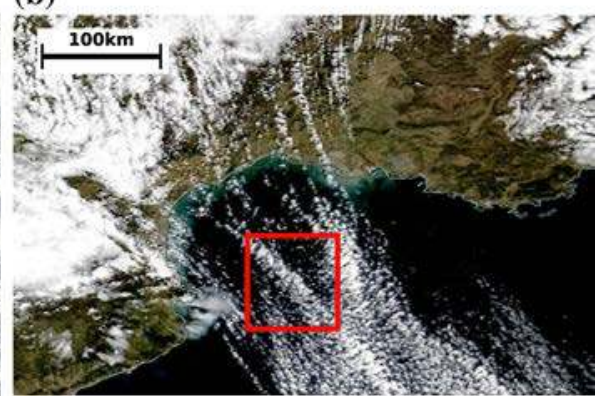

Fig. 16 Photos from MODIS instrumentation over the Gulf of Lion on, a 13 March 2013 at 1010 UTC, and b 14 March 2013 at 1050 UTC. The red square represents the area where the aircraft observations were performed

in connection with the dry-air advection observed during the $\mathrm{CAO}$ event. In this way, the MODIS image for the following morning (Fig. 16b) may be more representative of the situation analyzed here, because the meteorological conditions are approximately consistent from the afternoon of the 13 March to the evening of 14 March (see Brilouet et al. (2017), Fig. 1). In the latter image, cloud organization along the mean wind direction is clearly visible.

It is easier to examine the cloud cover from the output fields of the LES. It is characterized in Fig. 17 from the time series of the fractional area covered by clouds, and of the lifting condensation level (LCL), computed at each horizontal grid point of the model from the pressure, temperature and moisture values at the height of $50 \mathrm{~m}$ above the surface. The LCL represents the height at which an air parcel, adiabatically raised while keeping its specific humidity, becomes saturated. The LCL time series represented in the figure is the average value over the horizontal domain of the model $(25 \mathrm{~km} \times 10 \mathrm{~km})$. Figure 17 shows that clouds were present all along the LES, with an average cloud fractional area of 64\%. LCL values vary little during the simulation (around $690 \mathrm{~m}$ on average), and are close to the MABL height, indicating that clouds form at the top of the MABL. It is easier to examine the cloud cover from the output fields of the LES model. Figure 17 presents the time series of the fractional area covered by clouds, and of the lifting condensation level (LCL) computed at each horizontal grid point of the model from the pressure, temperature and moisture values at the height of $50 \mathrm{~m}$ above the surface. The LCL represents the height at which an air parcel adiabatically raised at constant specific humidity becomes saturated. The LCL time series is the average value over the horizontal domain of the model $(25 \mathrm{~km} \times 10 \mathrm{~km})$. Figure 17 reveals that the clouds were present throughout the LES run, with an average cloud fractional area of $64 \%$. The LCL values vary little during the simulation (around $690 \mathrm{~m}$ on average), and are close to the MABL height, indicating that clouds form at the MABL top.

Figure 18 presents the horizontal field at 1545 UTC of the maximum value along the vertical coordinate of the liquid water content. A non-zero value means that liquid water is present somewhere above the grid point considered. Let us recall that the horizontal LES domain is oriented in such a way that the mean MABL wind direction is parallel to the long axis of the domain. The cloud structure is clearly elongated along the mean wind direction, with stripes evoking both the periodic structure of the cross-wind observations and the horizontal cross-sections of the vertical velocity component and moisture fields of the LES results (Figs. 3 and 10). This is consistent with clouds forming at the top of the ascending branches of the convective rolls. 


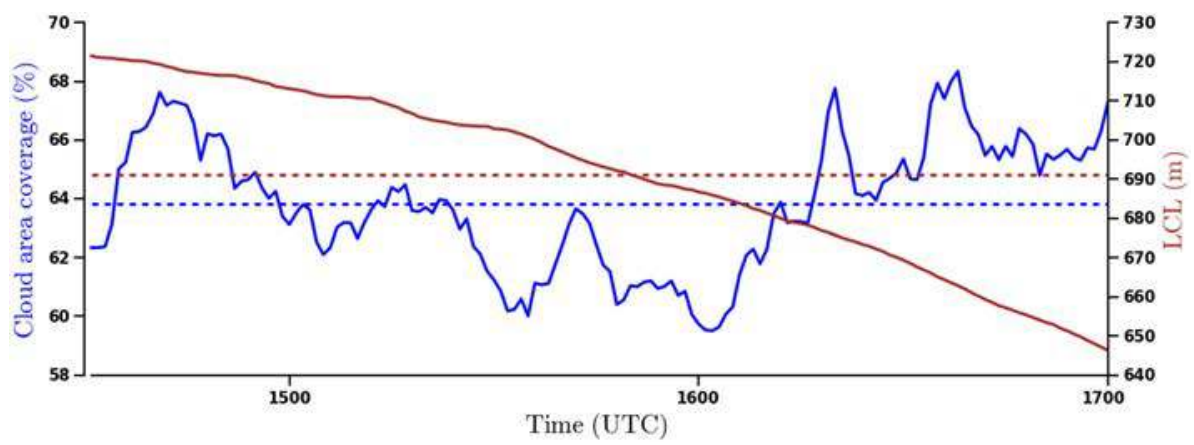

Fig. 17 Time series of the cloud fractional area computed from the LES results, and of the LCL between 1430 and 1700 UTC. At each timestep of the LES run, the LCL is the average of the values computed for the air parcels at $50 \mathrm{~m}$ above the surface

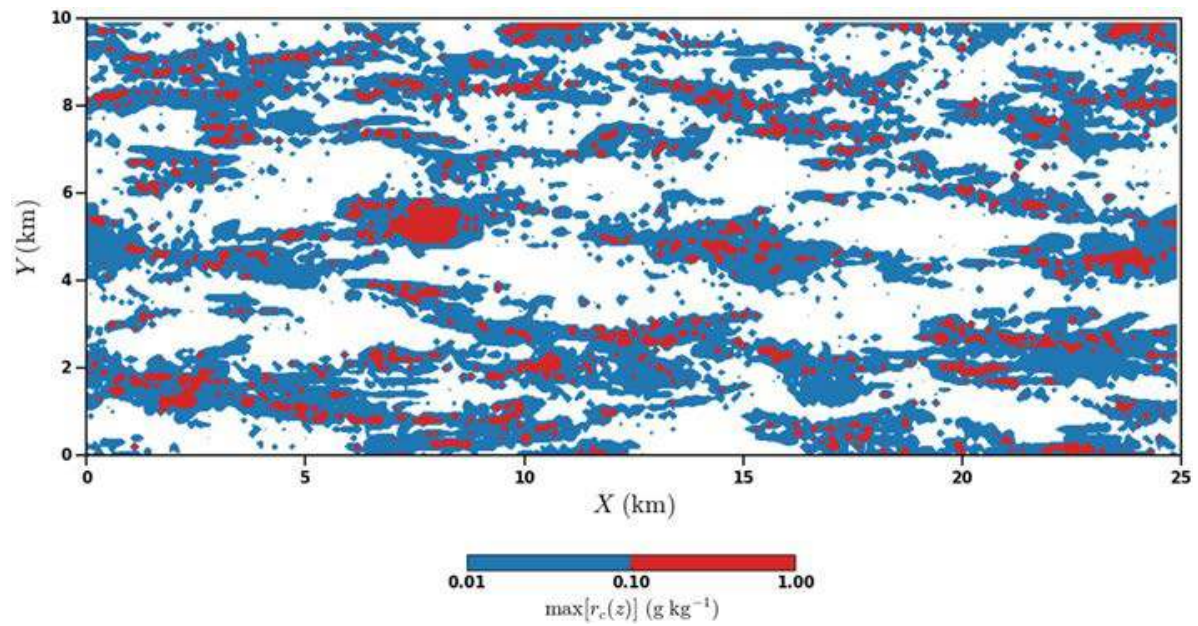

Fig. 18 Simulated horizontal field at 1545 UTC of the liquid water content. The represented value is the maximum over the vertical coordinate, regardless of the height at which it is computed

\section{References}

Agee E, Gluhovsky A (1999) LES model sensitivities to domains, grids, and large-eddy timescales. J Atmos Sci 56(4):599-604. https://doi.org/10.1175/1520-0469(1999)056<0599:LMSTDG>2.0.CO;2

Andreas EL, Persson POG, Hare JE (2008) A bulk turbulent air-sea flux algorithm for high-wind, spray conditions. J Phys Oceanogr 38(7):1581-1596. https://doi.org/10.1175/2007JPO3813.1

Andreas EL, Mahrt L, Vickers D (2015) An improved bulk air-sea surface flux algorithm, including spraymediated transfer. Q J R Meteorol Soc 141(687):642-654. https://doi.org/10.1002/qj.2424

Andreas EL, Vlahos P, Monahan E (2016) The potential role of sea spray droplets in facilitating air-sea gas transfer. In: IOP conference series: earth and environmental science. IOP Publishing, vol 35, p 012003. https://doi.org/10.1088/1755-1315/35/1/012003

Atkinson BW, Zhang JW (1996) Mesoscale shallow convection in the atmosphere. Rev Geophys 34(4):403431. https://doi.org/10.1029/96RG02623

Belamari S (2005) Report on uncertainty estimates of an optimal bulk formulation for surface turbulent fluxes. MERSEA IP Deliverable D 4.1.2:29

Bellon G, Stevens B (2012) Using the sensitivity of large-eddy simulations to evaluate atmospheric boundary layer models. J Atmos Sci 69(5):1582-1601. https://doi.org/10.1175/JAS-D-11-0160.1 
Bougeault P, Lacarrère P (1989) Parameterization of orography-induced turbulence in a mesobeta-scale model. Mon Weather Rev 117(8):1872-1890. https://doi.org/10.1175/1520-0493(1989)117<1872:POOITI>2. $0 . \mathrm{CO} ; 2$

Brasseur JG (2010) Designing large-eddy simulation of the turbulent boundary layer to capture law-of-the-wall scaling. Phys Fluids 22(2):021303. https://doi.org/10.1063/1.3319073

Brient F, Couvreux F, Villefranque N, Rio C, Honnert R (2019) Object-oriented identification of coherent structures in large eddy simulations: importance of downdrafts in stratocumulus. Geophys Res Lett. https://doi.org/10.1029/2018GL081499

Brilouet PE, Durand P, Canut G (2017) The marine atmospheric boundary layer under strong wind conditions: organized turbulence structure and flux estimates by airborne measurements. J Geophys Res Atmos 122(4):2115-2130. https://doi.org/10.1002/2016JD025960

Brooks IM, Rogers DP (1997) Aircraft observations of boundary layer rolls off the coast of California. J Atmos Sci 54(14):1834-1849. https://doi.org/10.1175/1520-0469(1997)054<1834:AOOBLR>2.0.CO;2

Brosse F, Leriche M, Mari C, Couvreux F (2018) LES study of the impact of moist thermals on the oxidative capacity of the atmosphere in southern West Africa. Atmos Chem Phys 18(9):6601-6624. https://doi. org/10.5194/acp-18-6601-2018

Brown RA (1980) Longitudinal instabilities and secondary flows in the planetary boundary layer: a review. Rev Geophys 18(3):683. https://doi.org/10.1029/RG018i003p00683

Brunke MA, Fairall CW, Zeng X, Eymard L, Curry JA (2003) Which bulk aerodynamic algorithms are least problematic in computing ocean surface turbulent fluxes? J Clim 16(4):619-635. https://doi.org/10.1175/ 1520-0442(2003)016<0619:WBAAAL> 2.0.CO;2

Brümmer B, Pohlmann S (2000) Wintertime roll and cell convection over Greenland and Barents Sea regions: a climatology. J Geophys Res Atmos 105(D12):15559-15566. https://doi.org/10.1029/1999JD900841

Brümmer B, Bakan S, Hinzpeter H (1985) Kontur: observations of cloud streets and open cellular structures. Dyn Atmos Oceans 9(3):281-296. https://doi.org/10.1016/0377-0265(85)90024-7

Caughey SJ, Kitchen M, Leighton JR (1983) Turbulence structure in convective boundary layers and implications for diffusion. Boundary-Layer Meteorol 25(4):345-352. https://doi.org/10.1007/BF02041153

Chinita MJ, Matheou G, Teixeira J (2018) A joint probability density-based decomposition of turbulence in the atmospheric boundary layer. Mon Weather Rev 146(2):503-523. https://doi.org/10.1175/MWR-D17-0166.1

Chlond A (1992) Three-dimensional simulation of cloud street development during a cold air outbreak. Boundary-Layer Meteorol 58(1-2):161-200. https://doi.org/10.1007/BF00120757

Chou SH (1993) A comparison of airborne eddy correlation and bulk aerodynamic methods for ocean-air turbulent fluxes during cold-air outbreaks. Boundary-Layer Meteorol 64(1-2):75-100. https://doi.org/ $10.1007 / \mathrm{BF} 00705663$

Chou SH, Ferguson MP (1991) Heat fluxes and roll circulations over the western Gulf Stream during an intense cold-air outbreak. Boundary-Layer Meteorol 55(3):255-281. https://doi.org/10.1007/BF00122580

Chou SH, Zimmerman J (1989) Bivariate conditional sampling of buoyancy flux during an intense cold-air outbreak. Boundary-Layer Meteorol 46(1-2):93-112. https://doi.org/10.1007/BF00118448

Colella P, Woodward PR (1984) The piecewise parabolic method (PPM) for gas-dynamical simulations. J Comput Phys 54(1):174-201. https://doi.org/10.1016/0021-9991(84)90143-8

Cook PA, Renfrew IA (2015) Aircraft-based observations of air-sea turbulent fluxes around the British Isles: observations of air-sea fluxes. Q J R Meteorol Soc 141(686):139-152. https://doi.org/10.1002/qj.2345

Couvreux F, Guichard F, Redelsperger JL, Kiemle C, Masson V, Lafore JP, Flamant C (2005) Water-vapour variability within a convective boundary-layer assessed by large-eddy simulations and IHOP_2002 observations. Q J R Meteorol Soc 131(611):2665-2693. https://doi.org/10.1256/qj.04.167

Couvreux F, Hourdin F, Rio C (2010) Resolved versus parametrized boundary-layer plumes. Part I: a parametrization-oriented conditional sampling in large-eddy simulations. Boundary-Layer Meteorol 134(3):441-458. https://doi.org/10.1007/s10546-009-9456-5

Cuxart J, Bougeault P, Redelsperger JL (2000) A turbulence scheme allowing for mesoscale and large-eddy simulations. Q J R Meteorol Soc 126(562):1-30. https://doi.org/10.1002/qj.49712656202

Darbieu C, Lohou F, Lothon M, Vilà-Guerau de Arellano J, Couvreux F, Durand P, Pino D, Patton EG, Nilsson E, Blay-Carreras E, Gioli B (2015) Turbulence vertical structure of the boundary layer during the afternoon transition. Atmos Chem Phys 15(17):10071-10086. https://doi.org/10.5194/acp-15-10071-2015

Deardorff JW (1970) Convective velocity and temperature scales for the unstable planetary boundary layer and for Rayleigh convection. J Atmos Sci 27(8):1211-1213. https://doi.org/10.1175/15200469(1970)027<1211:CVATSF> 2.0.CO;2

Deardorff JW (1980) Stratocumulus-capped mixed layers derived from a three-dimensional model. BoundaryLayer Meteorol 18(4):495-527. https://doi.org/10.1007/BF00119502 
Deardorff JW, Willis GE (1985) Further results from a laboratory model of the convective planetary boundary layer. Boundary-Layer Meteorol 32(3):205-236. https://doi.org/10.1007/BF00121880

de Roode SR, Duynkerke PG, Jonker HJJ (2004) Large-eddy simulation: how large is large enough? J Atmos Sci 61(4):403-421. https://doi.org/10.1175/1520-0469(2004)061<0403:LSHLIL>2.0.CO;2

de Roode SR, Frederikse T, Siebesma AP, Ackerman AS, Chylik J, Field PR, Fricke J, Gryschka M, Hill A, Honnert R, Krueger SK, Lac C, Lesage AT, Tomassini L (2019) Turbulent transport in the gray zone: a large eddy model intercomparison study of the CONSTRAIN cold air outbreak case. J Adv Model Earth Syst 11(3):597-623. https://doi.org/10.1029/2018MS001443

Durran DR (1989) Improving the anelastic approximation. J Atmos Sci 46(11):1453-1461. https://doi.org/10. 1175/1520-0469(1989)046<1453:ITAA>2.0.CO;2

Emanuel K (2018) 100 years of progress in tropical cyclone research. Meteorol Monogr 59:15.1-15.68. https:// doi.org/10.1175/AMSMONOGRAPHS-D-18-0016.1

Estournel C, Testor P, Taupier-Letage I, Bouin MN, Coppola L, Durand P, Conan P, Bosse A, Brilouet PE, Beguery L, Belamari S, Béranger K, Beuvier J, Bourras D, Canut G, Doerenbecher A, Durrieu de Madron X, D’Ortenzio F, Drobinski P, Ducrocq V, Fourrié N, Giordani H, Houpert L, Labatut L, Lebeaupin Brossier C, Nuret M, Prieur L, Roussot O, Seyfried L, Somot S (2016) HyMeX-SOP2: the field campaign dedicated to dense water formation in the Northwestern Mediterranean. Oceanography 29(4):196-206. https://doi.org/10.5670/oceanog.2016.94

Etling D, Brown RA (1993) Roll vortices in the planetary boundary layer: a review. Boundary-Layer Meteorol 65(3):215-248. https://doi.org/10.1007/BF00705527

Etling D, Raasch S (1987) Numerical simulation of vortex roll development during a cold air outbreak. Dyn Atmos Oceans 10(4):277-290. https://doi.org/10.1016/0377-0265(87)90021-2

Fairall CW, Bradley EF, Hare JE, Grachev AA, Edson JB (2003) Bulk parameterization of air-sea fluxes: updates and verification for the COARE algorithm. J Clim 16(4):571-591. https://doi.org/10.1175/15200442(2003)016<0571:BPOASF> 2.0.CO;2

Flamant C (2003) Alpine lee cyclogenesis influence on air-sea heat exchanges and marine atmospheric boundary layer thermodynamics over the western Mediterranean during a Tramontane/Mistral event. J Geophys Res Oceans. https://doi.org/10.1029/2001JC001040

Flamant C, Pelon J (1996) Atmospheric boundary-layer structure over the mediterranean during a tramontane event. Q J R Meteorol Soc 122(536):1741-1778. https://doi.org/10.1002/qj.49712253602

Fourrié N, Nuret M, Brousseau P, Caumont O, Doerenbecher A, Wattrelot E, Moll P, Bénichou H, Puech D, Bock O, Bosser P, Chazette P, Flamant C, Di Girolamo P, Richard E, Said F (2019) The AROMEWMED reanalyses of the first special observation period of the Hydrological cycle in the Mediterranean experiment (HyMeX). Geosci Model Dev 12(7):2657-2678. https://doi.org/10.5194/gmd-12-2657-2019

Fourrié N, Bresson E, Nuret M, Jany C, Brousseau P, Doerenbecher A, Kreitz M, Nuissier O, Sevault E, Bénichou H, Amodei M, Pouponneau F (2015) AROME-WMED, a real-time mesoscale model designed for the HyMeX special observation periods. Geosci Model Dev 8(7):1919-1941. https://doi.org/10.5194/ gmd-8-1919-2015

Grossman RL (1982) An analysis of vertical velocity spectra obtained in the bomex fair-weather, trade-wind boundary layer. Boundary-Layer Meteorol 23(3):323-357. https://doi.org/10.1007/BF00121120

Grossman RL (1984) Bivariate conditional sampling of moisture flux over a tropical ocean. J Atmos Sci 41(22):3238-3254. https://doi.org/10.1175/1520-0469(1984)041<3238:BCSOMF>2.0.CO;2

Grossman RL, Betts AK (1990) Air-sea interaction during an extreme cold air outbreak from the Eastern Coast of the United States. Mon Weather Rev 118(2):324-342. https://doi.org/10.1175/15200493(1990) 118<0324:AIDAEC > 2.0.CO;2

Gryschka M, Raasch S (2005) Roll convection during a cold air outbreak: a large eddy simulation with stationary model domain. Geophys Res Lett. https://doi.org/10.1029/2005GL022872

Gryschka M, Fricke J, Raasch S (2014) On the impact of forced roll convection on vertical turbulent transport in cold air outbreaks. J Geophys Re Atmos 119(22):12,513-12,532. https://doi.org/10.1002/2014JD022160

Guichard F, Couvreux F (2017) A short review of numerical cloud-resolving models. Tellus A Dyn Meteorol Oceanogr 69(1):1373578. https://doi.org/10.1080/16000870.2017.1373578

Honnert R, Masson V, Couvreux F (2011) A diagnostic for evaluating the representation of turbulence in atmospheric models at the kilometric scale. J Atmos Sci 68(12):3112-3131. https://doi.org/10.1175/ JAS-D-11-061.1

Hourdin F, Couvreux F, Menut L (2002) Parameterization of the dry convective boundary layer based on a mass flux representation of thermals. J Atmos Sci 59(6):1105-1123. https://doi.org/10.1175/15200469(2002)059<1105:POTDCB > 2.0.CO;2

Jonker HJJ, Duynkerke PG, Cuijpers JWM (1999) Mesoscale fluctuations in scalars generated by boundary layer convection. J Atmos Sci 56(5):801-808. https://doi.org/10.1175/1520-0469(1999)056<0801: MFISGB $>2.0 . \mathrm{CO} ; 2$ 
Lac C, Chaboureau JP, Masson V, Pinty JP, Tulet P, Escobar J, Leriche M, Barthe C, Aouizerats B, Augros C, Aumond P, Auguste F, Bechtold P, Berthet S, Bielli S, Bosseur F, Caumont O, Cohard JM, Colin J, Couvreux F, Cuxart J, Delautier G, Dauhut T, Ducrocq V, Filippi JB, Gazen D, Geoffroy O, Gheusi F, Honnert R, Lafore JP, Lebeaupin Brossier C, Libois Q, Lunet T, Mari C, Maric T, Mascart P, Mogé M, Molinié G, Nuissier O, Pantillon F, Peyrillé P‘, Pergaud J, Perraud E, Pianezze J, Redelsperger JL, Ricard D, Richard E, Riette S, Rodier Q, Schoetter R, Seyfried L, Stein J, Suhre K, Taufour M, Thouron O, Turner S, Verrelle A, Vié B, Visentin F, Vionnet V, Wautelet P (2018) Overview of the Meso-NH model version 5.4 and its applications. Geosci Model Dev 11(5):1929-1969. https://doi.org/10.5194/gmd-111929-2018

Lane TP, Clark TL (2002) Gravity waves generated by the dry convective boundary layer: two-dimensional scale selection and boundary-layer feedback. Q J R Meteorol Soc 128(583):1543-1570. https://doi.org/ 10.1002/qj.200212858308

Lebeaupin Brossier C, Ducrocq V, Giordani H (2008) Sensitivity of three mediterranean heavy rain events to two different sea surface fluxes parameterizations in high-resolution numerical modeling. J Geophys Res Atmos. https://doi.org/10.1029/2007JD009613

LeMone MA (1976) Modulation of turbulence energy by longitudinal rolls in an unstable planetary boundary layer. J Atmos Sci 33(7):1308-1320. https://doi.org/10.1175/1520-0469(1976)033<1308:MOTEBL>2. $0 . \mathrm{CO} ; 2$

Li Q, Gentine P, Mellado JP, McColl KA (2018) Implications of nonlocal transport and conditionally averaged statistics on Monin-Obukhov similarity theory and Townsend's attached eddy hypothesis. J Atmos Sci 75(10):3403-3431. https://doi.org/10.1175/JAS-D-17-0301.1

Liu AQ, Moore GWK, Tsuboki K, Renfrew IA (2004) A high-resolution simulation of convective roll clouds during a cold-air outbreak. Geophys Res Lett. https://doi.org/10.1029/2003GL018530

Liu WT, Katsaros KB, Businger JA (1979) Bulk parameterization of air-sea exchanges of heat and water vapor including the molecular constraints at the interface. J Atmos Sci 36(9):1722-1735. https://doi.org/10. 1175/1520-0469(1979)036<1722:BPOASE>2.0.CO;2

Lohou F, Druilhet A, Campistron B, Redelsperger JL, Saïd F (2000) Numerical study of the impact of coherent structures on vertical transfers in the atmospheric boundary layer. Boundary-Layer Meteorol 97(3):361383. https://doi.org/10.1023/A:1002641728075

Lothon M, Couvreux F, Donier S, Guichard F, Lacarrère P, Lenschow DH, Noilhan J, Saïd F (2007) Impact of coherent eddies on airborne measurements of vertical turbulent fluxes. Boundary-Layer Meteorol 124(3):425-447. https://doi.org/10.1007/s10546-007-9182-9

Lunet T, Lac C, Auguste F, Visentin F, Masson V, Escobar J (2017) Combination of WENO and explicit Runge-Kutta methods for wind transport in the Meso-NH model. Mon Weather Rev 145(9):3817-3838. https://doi.org/10.1175/MWR-D-16-0343.1

Melfi SH, Palm SP (2012) Estimating the orientation and spacing of midlatitude linear convective boundary layer features: cloud streets. J Atmos Sci 69(1):352-364. https://doi.org/10.1175/JAS-D-11-070.1

Mertens C, Schott F (1998) Interannual variability of deep-water formation in the Northwestern Mediterranean. J Phys Oceanogr 28(7):1410-1424. https://doi.org/10.1175/1520-0485(1998)028<1410:IVODWF>2.0. $\mathrm{CO} ; 2$

Miao Q, Geerts B, LeMone M (2006) Vertical velocity and buoyancy characteristics of coherent echo plumes in the convective boundary layer, detected by a profiling airborne radar. J Appl Meteorol Clim 45(6):838855. https://doi.org/10.1175/JAM2375.1

Moon IJ, Ginis I, Hara T, Thomas B (2007) A physics-based parameterization of air-sea momentum flux at high wind speeds and its impact on hurricane intensity predictions. Mon Weather Rev 135(8):2869-2878. https://doi.org/10.1175/MWR3432.1

Morrison H, De Boer G, Feingold G, Harrington J, Shupe MD, Sulia K (2012) Resilience of persistent arctic mixed-phase clouds. Nat Geosci 5(1):11. https://doi.org/10.1038/ngeo1332

Müller G, Chlond A (1996) Three-dimensional numerical study of cell broadening during cold-air outbreaks. Boundary-Layer Meteorol 81(3-4):289-323. https://doi.org/10.1007/BF02430333

Müller G, Brümmer B, Alpers W (1999) Roll convection within an Arctic cold-air outbreak: interpretation of in situ aircraft measurements and spaceborne SAR imagery by a three-dimensional atmospheric model. Mon Weather Rev 127(3):363-380. https://doi.org/10.1175/1520-0493(1999)127<0363:RCWAAC>2. $0 . \mathrm{CO} ; 2$

Park SB, Gentine P, Schneider K, Farge M (2016) Coherent structures in the boundary and cloud layers: role of updrafts, subsiding shells, and environmental subsidence. J Atmos Sci 73(4):1789-1814. https://doi. org/10.1175/JAS-D-15-0240.1

Pergaud J, Masson V, Malardel S, Couvreux F (2009) A parameterization of dry thermals and shallow cumuli for mesoscale numerical weather prediction. Boundary-Layer Meteorol 132(1):83-106. https://doi.org/ 10.1007/s10546-009-9388-0 
Pinty JP, Jabouille P (1998) A mixed-phase cloud parameterization for use in mesoscale non-hydrostatic model: simulations of a squall line and of orographic precipitations. In: Proceedings of Conference on Cloud Physics, pp 217-220

Pope S (2000) Turbulent flows. Cambridge University Press, Cambridge

Redelsperger JL, Sommeria G (1986) Three-dimensional simulation of a convective storm: sensitivity studies on subgrid parameterization and spatial resolution. J Atmos Sci 43(22):2619-2635. https://doi.org/10. 1175/1520-0469(1986)043<2619:TDSOAC>2.0.CO;2

Renfrew IA, Moore GWK (1999) An extreme cold-air outbreak over the Labrador sea: roll vortices and air-sea interaction. Mon Weather Rev 127(10):2379-2394. https://doi.org/10.1175/1520-0493(1999)127<2379: AECAOO> 2.0.CO;2

Ricard D, Lac C, Riette S, Legrand R, Mary A (2013) Kinetic energy spectra characteristics of two convectionpermitting limited-area models AROME and Meso-NH. Q J R Meteorol Soc 139(674):1327-1341. https://doi.org/10.1002/qj.2025

Salesky ST, Anderson W (2018) Buoyancy effects on large-scale motions in convective atmospheric boundary layers: implications for modulation of near-wall processes. J Fluid Mech 856:135-168. https://doi.org/ $10.1017 / \mathrm{jfm} .2018 .711$

Salesky ST, Chamecki M, Bou-Zeid E (2017) On the nature of the transition between roll and cellular organization in the convective boundary layer. Boundary-Layer Meteorol 163(1):41-68. https://doi.org/10. 1007/s10546-016-0220-3

Seity Y, Brousseau P, Malardel S, Hello G, Bénard P, Bouttier F, Lac C, Masson V (2011) The AROMEFrance convective-scale operational model. Mon Weather Rev 139(3):976-991. https://doi.org/10.1175/ 2010MWR3425.1

Shin HH, Hong SY (2013) Analysis of resolved and parameterized vertical transports in convective boundary layers at gray-zone resolutions. J Atmos Sci 70(10):3248-3261. https://doi.org/10.1175/JAS-D-12-0290. 1

Skamarock WC (2004) Evaluating mesoscale nwp models using kinetic energy spectra. Mon Weather Rev 132(12):3019-3032. https://doi.org/10.1175/MWR2830.1

Smedman A, Högström U, Sahleé E, Drennan WM, Kahma KK, Pettersson H, Zhang F (2009) Observational study of marine atmospheric boundary layer characteristics during swell. J Atmos Sci 66(9):2747-2763. https://doi.org/10.1175/2009JAS2952.1

Soares P, Miranda P, Siebesma A, Teixeira J (2004) An eddy-diffusivity/mass-flux parametrization for dry and shallow cumulus convection. Q J R Meteorol Soc 130(604):3365-3383. https://doi.org/10.1256/qj.03. 223

Sullivan PP, Patton EG (2011) The effect of mesh resolution on convective boundary layer statistics and structures generated by large-eddy simulation. J Atmos Sci 68(10):2395-2415. https://doi.org/10.1175/ JAS-D-10-05010.1

Sullivan PP, McWilliams JC, Moeng CH (1994) A subgrid-scale model for large-eddy simulation of planetary boundary-layer flows. Boundary-Layer Meteorol 71(3):247-276. https://doi.org/10.1007/BF00713741

Sullivan PP, Horst TW, Lenschow DH, Moeng CH, Weil JC (2003) Structure of subfilter-scale fluxes in the atmospheric surface layer with application to large-eddy simulation modelling. J Fluid Mech 482:101139. https://doi.org/10.1017/S0022112003004099

Sun J, Lenschow DH, LeMone MA, Mahrt L (2016) The role of large-coherent-eddy transport in the atmospheric surface layer based on CASES-99 observations. Boundary-Layer Meteorol 160(1):83-111. https://doi.org/10.1007/s10546-016-0134-0

Sykes RI, Henn DS (1989) Large-eddy simulation of turbulent sheared convection. J Atmos Sci 46(8):11061118. https://doi.org/10.1175/1520-0469(1989)046<1106:LESOTS>2.0.CO;2

Thurston W, Fawcett RJB, Tory KJ, Kepert JD (2016) Simulating boundary-layer rolls with a numerical weather prediction model. Q J R Meteorol Soc 142(694):211-223. https://doi.org/10.1002/qj.2646

Tomassini L, Field PR, Honnert R, Malardel S, McTaggart-Cowan R, Saitou K, Noda AT, Seifert A (2017) The "Grey Zone" cold air outbreak global model intercomparison: a cross evaluation using large-eddy simulations. J Adv Model Earth Syst 9(1):39-64. https://doi.org/10.1002/2016MS000822

Townsend AA (1961) Equilibrium layers and wall turbulence. J Fluid Mech 11(1):97-120. https://doi.org/10. 1017/S0022112061000883

Tsinober A, Levich E (1983) On the helical nature of three-dimensional coherent structures in turbulent flows. Phys Lett A 99(6-7):321-324. https://doi.org/10.1016/0375-9601(83)90896-4

Vogel R, Nuijens L, Stevens B (2016) The role of precipitation and spatial organization in the response of tradewind clouds to warming. J Adv Model Earth Syst 8(2):843-862. https://doi.org/10.1002/2015MS000568

Weckwerth TM, Wilson JW, Wakimoto RM (1996) Thermodynamic variability within the convective boundary layer due to horizontal convective rolls. Mon Weather Rev 124(5):769-784. https://doi.org/10.1175/ 1520-0493(1996)124<0769:TVWTCB>2.0.CO;2 
Weller RA, Bradley F, Lukas R (2004) The interface or air-sea flux component of the TOGA coupled oceanatmosphere response experiment and its impact on subsequent air-sea interaction studies. J Atmos Ocean Technol 21(2):223-257. https://doi.org/10.1175/1520-0426(2004)021<0223:TIOAFC>2.0.CO;2

Wyngaard JC (1983) Lectures on the planetary boundary layer. In: Lilly DK, Gal-Chen T (eds) Mesoscale meteorology - theories, observations and models. Springer, Dordrecht, pp 603-650. https://doi.org/10. 1007/978-94-017-2241-4_33

Young GS (1988) Turbulence structure of the convective boundary layer. Part II. Phonenix 78 aircraft observations of thermals and their environment. J Atmos Sci 45(4):727-735. https://doi.org/10.1175/15200469(1988)045<0727:TSOTCB>2.0.CO;2

Young GS, Kristovich DAR, Hjelmfelt MR, Foster RC (2002) Rolls, streets, waves, and more: a review of quasi-two-dimensional structures in the atmospheric boundary layer. Bull Am Meteorol Soc 83(7):9971001. https://doi.org/10.1175/1520-0477(2002)083<0997:RSWAMA>2.3.CO;2

Zurn-Birkhimer SM, Agee EM, Sorbjan Z (2005) Convective structures in a cold air outbreak over Lake Michigan during Lake-ICE. J Atmos Sci 62(7):2414-2432. https://doi.org/10.1175/JAS3494.1 